سيناريوهات مقترحة لتطوير دور المؤسسات التعليمية الجامعية في تعزيز قيم مشاركة الشباب الفلسطيني في العمل التطوعي

معتصم وليد محمد العقاد 
سيناريوهات مقترحة لتطوير دور المؤسسات التعليمية الجامعية في تعزيز قيم مشار كة الشباب الفلسطيني في العمل التطوعي

$$
\text { معتصم وليد محمد العقاد }
$$

محاضر أكاديمي بجامعة الأقصن، فلسطين

rafat_ewadi@hotmail.com

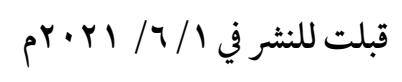

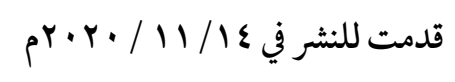

الملخص: هدفت الدراسة إلى وضع سيناريوهات مقترحة لتطوير دور المؤسسات التعليمية الجامعية في تعزيز قيم مشاركة الشباب الفلسطيني في العمل التطوعي، استخدمت الدراسة المنهج الوصفي مدري التحليلي والأسلوب الاستشرافي، وتم تطبيق استبانة مكونة من (Y^) فقرة علئ عينة الدراسة المكونة من (rrA) مبحوثاً، من محافظات غزة وهي (شمال غزة، غزة، الوسطى، خانيونس، رفح)، وتم اختيارهم بالطريقة العشوائية.

وقد كشفت النتائج أن المتوسط الحسابي الكلي لدور المؤسسات التعليمية الجامعية في تعزيز قيم

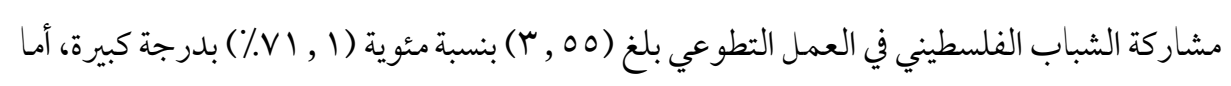
بالنسبة لمجالات الاستبانة فقد بلغ المتوسط الحسابي لمجال دور المؤسسات الجامعية الفلسطينية

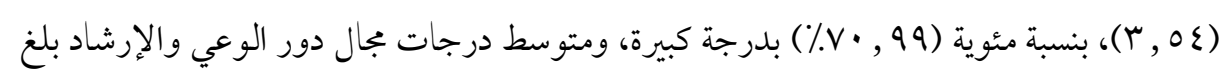

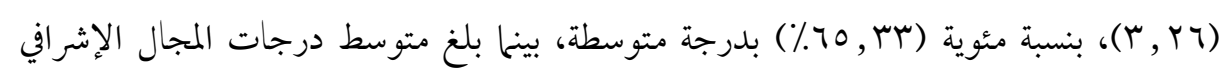

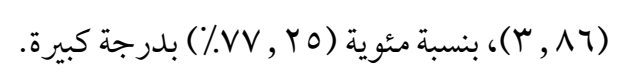

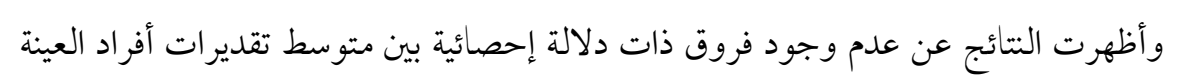
لمجالات دور المؤسسات التعليمية الجامعية في تعزيز قيم مشاركة الشباب الفلسطيني في العمل التطوعي

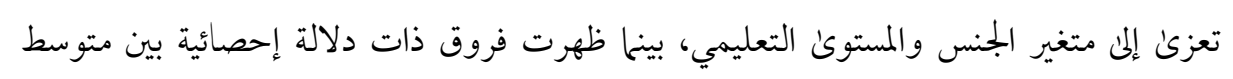
تقديرات أفر اد العينة تعزئ إلى متغير الفئة العمرية لصالح الشباب من أصحاب الفئة العمرية من 19 هب عام. وقدمت الدراسة السيناريوهات المقترحة متضمن التوصيات والمقترحات. 
الكلمات المفتاحية: سيناريوهات مقترحة، المؤسسات التعليمية الجامعية، الشباب الفلسطيني، قيم،

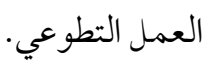




\title{
Develop a proposed scenario for developing the role of educational institutions in enhancing the values of Palestinian youth participation in volunteer work
}

Mutassem walid Alakad

Academic lecturer in Al-Aqsa University, Gaza, Palestine rafat_ewadi@hotmail.com

\begin{abstract}
The study aimed to develop a proposed scenario for developing the role of educational institutions in enhancing the values of Palestinian youth participation in volunteer work. The study used the descriptive and analytical approach, and a questionnaire consisting of (28) paragraphs was applied to the study sample consisting of (833) respondents from the governorates of Gaza They are (North Gaza, Gaza, Central, Khan Yunis, Rafah), and they were chosen randomly.

The results revealed that the overall arithmetic average of the role of educational institutions in promoting the values of Palestinian youth participation in volunteer work reached (3.55), with a percentage (71.1\%) to a large extent. (70.99\%) to a large degree, and the average score for the field of awareness and counseling reached (3.26), with a percentage $(65.33 \%)$ with a medium degree, while the average score for the supervisory field reached (3.86), with a percentage $(77.25 \%)$ to a large extent.

The results showed that there were no statistically significant differences between the average estimates of the sample members of the areas of the role of educational institutions in enhancing the values of Palestinian youth participation in volunteer work due to the variable of sex and educational level, while there were statistically significant differences between the average estimates of the sample members attributed to the variable of age groups. For the benefit of young people in the age group of 19-35 years. The study presented the proposed scenario, including recommendations and suggestions.
\end{abstract}

Key words: proposed scenario, educational institutions, Palestinian youth, values, volunteer work. 
إن العمل التطوعي عامل أساسي في بناء المجتمع ونشر التماسك الاجتهاعي بين المواطنين لأي

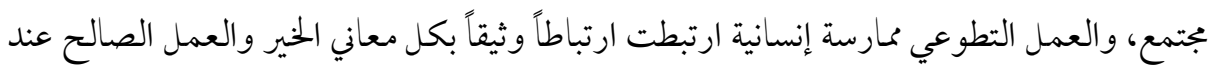
كل الناس منذ أن خلق الله الأرض وما عليها من بشر وكائنات، والعمل التطوعي أخذ عدة أشكال بدائية فرضتها الفطرة الإنسانية التي تجعل من الناس أن يهبو افي مساعدة بعضهم البعض لحاجة أفراد

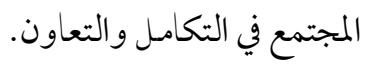
والمشاركة بالعمل التطوعي ظاهرة عالمية إنسانية فطرية، قبل أن تكون دينية، وهو أمر يدعو للترفع عن الدونية والأنانية، وحب الخير للجميع، لذلك كان ثوابه عند الله عظيم، وجعله مصداقاً للتدين وهذه الظاهرة الايجابية أصبحت منتشرة في أغلب المجتمعات الإنسانية، وأصبحت مادة

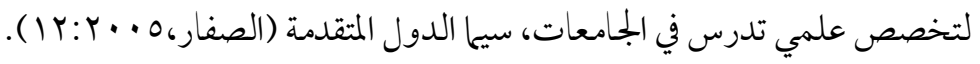
وتتباهئ الأمم المتحضرة اليوم بما عندها من إمكانيات، ومنها عدد المتطوعين في المجالات المختلفة، ذلك لأن العمل التطوعي يساهم في رفعة الأمة ويؤدي إلى تساند أفر ادها، وإيجادروح التعاون والمحبة (Home office, 2004)، وكلم) سما هدف المتطوع كان عمله أكثر قيمة، وأوسع خيراً، و أعظم فائدة، حيث كان ومازال ركيزة أساسية في بناء الحضارات ونشأة الدول وتقدمها بل أصبح

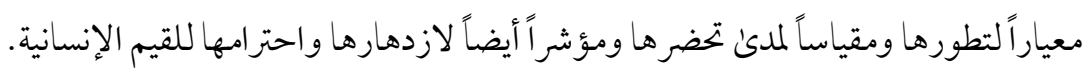
لذلك لجأت هذه الدول إلى نشر وتعميم ثقافة المشاركة بالعمل التطوعي في نفوس شبابها حيث أصبح التطوع قيمة إنسانية عالمية تغرس من خلال الوسائل المختلفة (الحازمي، 10 • ب: ع ع)، والإنسان بحاجة إلى أخيه الإنسان في كل زمان ومكان بغض النظر عن الجنس والعرق والدين واللون فالتطوع

قائم علن الحياد لأنه يقدم لجميع الناس بغض النظر عن أي اعتبارات أخرى (نصار، 10 • ب: Y I ).

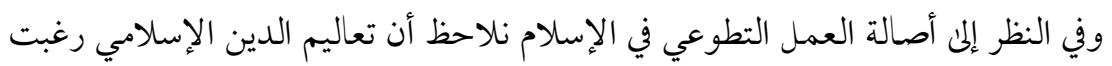
وحفزت على العمل الاجتماعي و فضلته على كثير من العبادات الفردية بل أصبح العمل التطوعي قربة إلى الله حيث يدخل العمل التطوعي في نطاق عمل الخير الذي يعد قربة للخالق عز وجل، فقد قال الله 


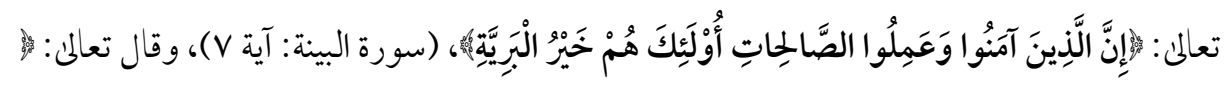

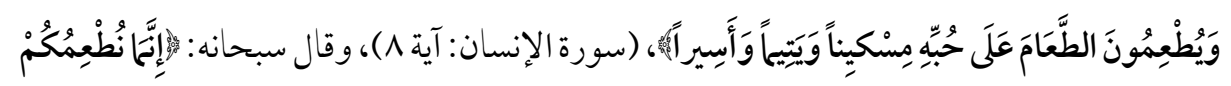

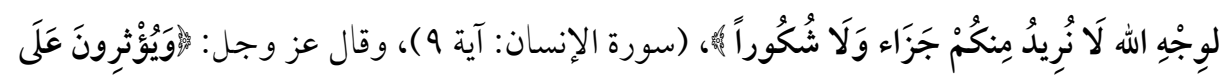

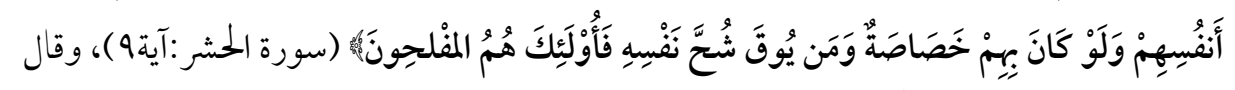

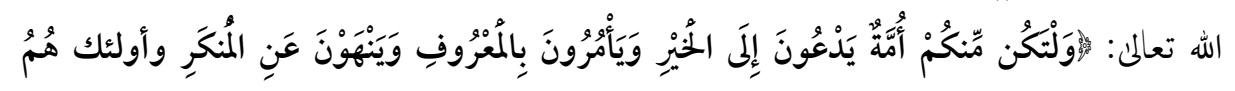

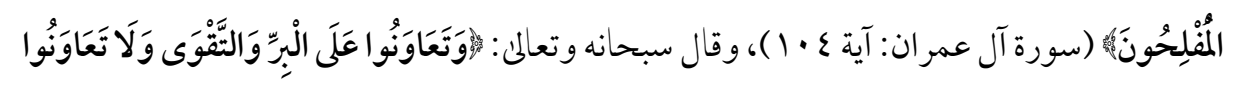

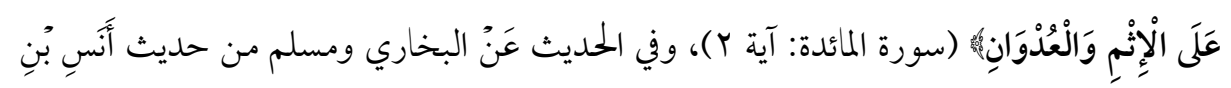

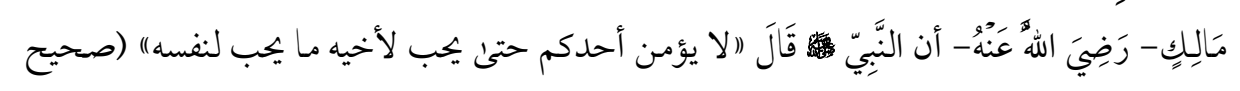
البخاري، كتاب الإيمان: صع ( )، وكثير من الأدلة الشرعية التي حثت وأوجبت العمل الخيري.

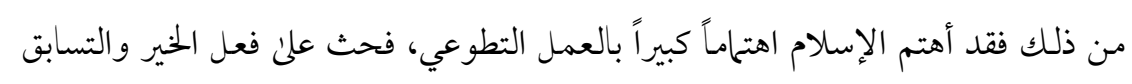
و التنافس فيه، وقد اعتبرت السنة النبوية أن خيرية البشر أصبحت تقاس بمدى تقديم المعونة والمساعدة

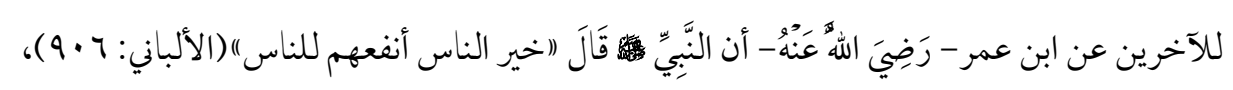

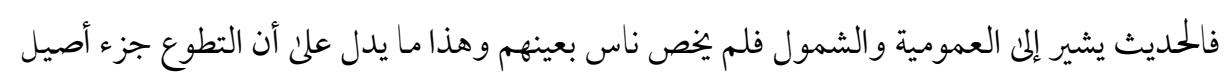

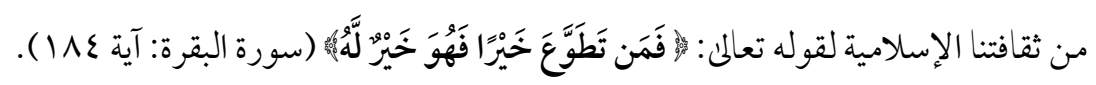
مما سبق تكون المشاركة بالعمل التطوعي قيمة إنسانية عالمية وجزء مهم في شريعتنا الإسلامية

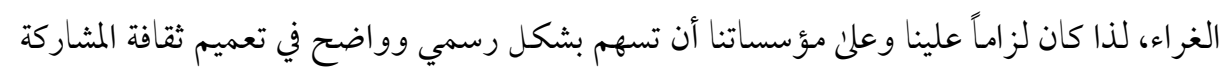
التطوعية لدىن طلبتنا خاصة، لأن مجتمعنا الفلسطيني أكثر من غيره بحاجة إلى جهو د التطوع و المتطوعين باعتباره ثقافة بجتمعية لكل فئات المجتمع. إن تعميم ثقافة المشاركة بالعمل التطوعي هي مسؤولية وطنية تقوم بها كافة المؤسسات الأهلية والحكومية خاصة والمؤسسات التعليمية عامة والجامعية خاصة التي تعنى بتنمية قيم العمل التطوعي

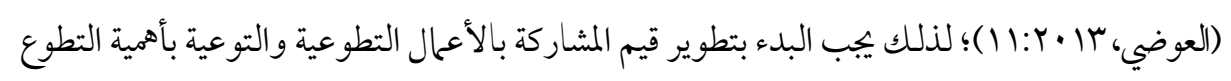


وبدوره في تقدم المجتمع، فقد أصبح العمل الاجتماعي التطوعي في عصرنا الراهن ركيزة أساسية في تطور المجتمعات وتنميتها. ويرئ الباحث أن المشاركة في العمل التطوعي أصبح ضرورة ملحه نتيجة للمشكلات التي يو اجهاه أفراد المجتمع الفلسطيني ومؤسساته الرسمية والأهلية كتعددو تعقد بعض الاحتياجات التي لم تكن موجودة في السابق، وأفرزها التطور الحضاري والتغيرات الاجتماعية والاقتصادية والسياسية والأمنية التي يشهدها المجتمع. تأسيسًا علن ما سبق فإن التعرف علن مدئ وجود قصور وخلل في عملية تتنميه قيم المشاركة بالعمل التطوعي والاشراف عليا بات ضرورة ملحة وحتمية، هذا إلى جانب أهمية الوقوف على مدئ الدور الذي تلعبه المؤسسات التعليمية الفلسطينية نحو دعم وتعزيز قيم مشاركة الشباب الفاعل في الأعمال التطوعية بما يلزم من أن تقوم به في بجالي التوعية والاشراف، تمكينًا للشباب من القيام برسالته الحقيقية في المجتمع وفقًا للمتغيرات السريعة المستمرة التي يتأثثر بها، وتتلخص مشكلة الدراسة في عدم وضوح دور المؤسسات التعليمية في تعزيز قيم مشاركة الشباب الفلسطيني في العمل التطوعي.

مشكلة البحث:

إن تنمية قيم المشاركة بالعمل التطوعي هي مسؤولية وطنية تقوم بها المؤسسات التعليمية علن

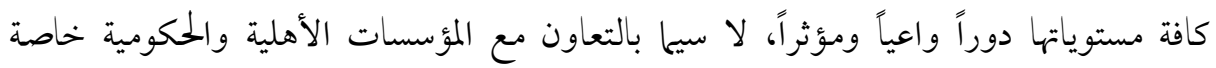
والمؤسسات التي تعنى بالعمل التطوعي؛ لذلك يجب البدء بتنمية قيم المشاركة بالأعمال التطوعية من

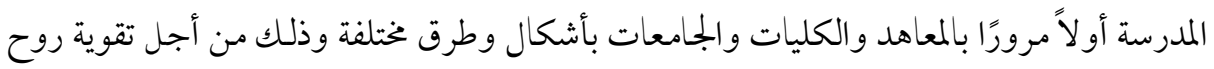
المشاركة بالعمل التطوعي في المجتمع. تأسيساً علن ما سبق فإن التعرف علن مدىن وجود قصور وخلل في عملية تثقيف وتنمية قيم المشاركة بالعمل التطوعي والاشراف عليها بات ضرورة ملحة وحتمية لدئ الشباب الفلسطيني، هذا إلى جانب أهمية الوقوف علن مدئ الدور الذي تلعبه المؤسسات التعليمية الجلمعية الفلسطينية نحو دعم 
وتعزيز قيم مشاركة الشباب في الأعمال التطوعية. في ضوء مـا تقدم يمكن أن تصاغ مشكلة الدراسة في

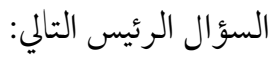
ما السيناريوهات المقترحة لتطوير دور المؤسسات التعليمية الجامعية في تعزيز قيم مشاركة الشباب

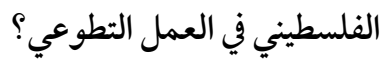
وقد تفرع من هذا السؤال الرئيس الأسئلة الفرعية التالية: ا. ما دور المؤسسات التعليمية الجامعية في تعزيز ثقافة قيم المشاركة بالعمل التطوعي لدئ

$$
\text { الشباب الفلسطيني من وجهة نظرهم؟ }
$$

r. مـا دور المؤسسات التعليمية الجامعية في تقديم الوعي والإرشاد لتعزيز قيم ثقافة المشاركة

$$
\text { بالعمل التطوعي لدئ الشباب الفلسطيني من وجهة نظرهم؟ }
$$

r. ما دور المؤسسات التعليمية الجامعية في الإشراف علن قيم المشاركة بالعمل التطوعي لدني

$$
\text { الشباب الفلسطيني من وجهة نظرهم؟ }
$$

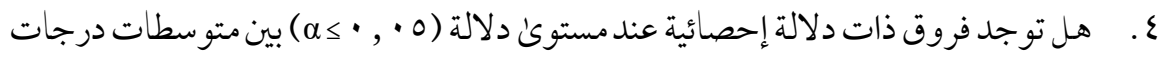
تقدير أفراد العينة لدور المؤسسات التعليمية الجامعية في تعزيز قيم مشاركة الشباب

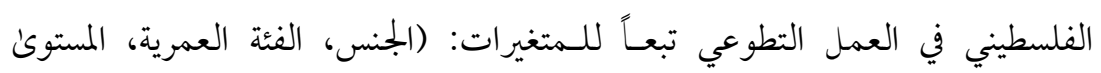
التعليمي)؟ ه. ما السيناريوهات المقترحة لتطوير المؤسسات التعليمية الجامعية في تعزيز قيم مشاركة الشباب الفلسطيني في العمل التطوعي؟

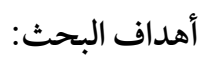
يهدف البحث إلى تحقيق ما يلي: ا. التعرف إلى دور المؤسسات التعليمية الجامعية في تعزيز ثقافة قيم المشاركة بالعمل التطوعي لدئ الشباب الفلسطيني. 
r. التعرف إلى دور المؤسسات التعليمية الجامعية في تقديم الوعي والإرشاد لتعزيز قيم ثقافة المشاركة بالعمل التطوعي لدى الشباب الفلسطيني. r. التعرف إلى دور المؤسسات التعليمية الجامعية في الإشر اف علن قيم المشاركة بالعمل التطوعي لدئ الشباب الفلسطيني.

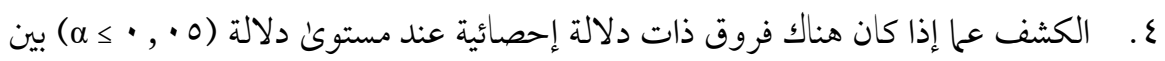
متوسطات درجات تقدير أفراد العينة لدور المؤسسات التعليمية الجامعية في تعزيز قيم مشاركة الشباب الفلسطيني في العمل التطوعي تبعـاً للـمتغيرات: (الجنس، الفئة العمرية،

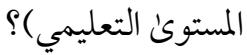
0. تقديم سيناريوهات مقترحة لتطوير دور المؤسسات التعليمية الجامعية في تعزيز قيم مشاركة الشباب الفلسطيني في العمل التطوعي.

$$
\text { تتمثل أهميــــة الدراســــة في الجوانب التالية: }
$$

1. أهمية العمل التطوعي الذي يمتد إلى مجالات متسعة من مجالات التنمية وتقدم المجتمع؛

$$
\text { للسعي لتطوير قيم التطوع لدئ الشباب الفلسطينين. }
$$

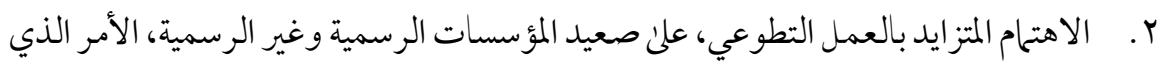
يقضي بضرورة وجود دراسة للتعرف إلى مستوكئ قيم العمل التطوعي في المجتمع الفلسطيني. r. تمثل هذه الدراسة استجابة للاتجاهات الحديثة، والتي تنادي بضرورة الاهتحام وتسليط الضوء على أهمية المشاركة بالعمل التطوعي في فلسطين بكافة المجالات. ع. إظهار بعض الاتجاهات المعاصرة في مجال المشاركات بالعمل التطوعي، ورصدها وتحليلها و تصنيفها والإفادة منها في برامج المؤسسات التعليمية الجامعية الفلسطينية. 
ه. قد تسهم في تقديم السيناريو المقترح التي يمكن أن يستفيد منها المسؤولون بالمؤسسات

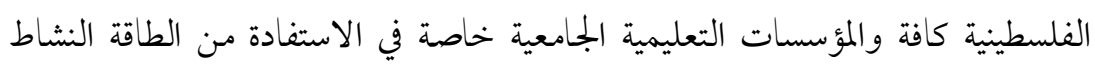

$$
\text { الحيوي للفئة المستهدفة اثناء إعداد الشباب وتنمية قيمهم. }
$$

7 . يمكن أن تستفيد المؤسسات التعليمية الجامعية الفلسطينية من نتائج هذه الدراسة في تطوير

$$
\begin{aligned}
& \text { آليات تعزيز قيم العمل التطوعي فلسطين. } \\
& \text { حدود البحث: } \\
& \text { يقتصر البحث على الحدود الآتية: }
\end{aligned}
$$

- حد الموضوع: تطوير دور المؤسسات التعليمية الجامعية في تعزيز قيم مشاركة الشباب

$$
\begin{aligned}
& \text { الفلسطيني في العمل التطوعي. } \\
& \text { - - الحد البشري: الشباب الفلسطيني. } \\
& \text { - - الحد المكاني: قطاع غزة. }
\end{aligned}
$$

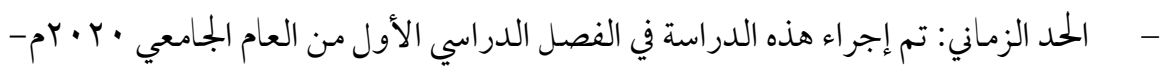

$$
\cdot r \cdot r)
$$

$$
\text { مصطلحات الدراسة الإجرائية: }
$$

- المشاركة التطوعية: أن تعمل المؤسسات الفلسطينية على تحقيق وتنمية مـا يمارسه الشاب من تلقاء نفسه عن رغبة واختيار في المجالات الإنسانية أو الاجتماعية بغرض واجب اجتماعي دون توقع أي مردود مادي، بها يكسبهم ثقافة العمل الخيري. - - قيم التطوع: هي منظومة الأخلاقيات والسلوكيات والمعايير والمارسات التي تعمل المؤسسات الفلسطينية من خلالها على حض ودفع أعضائها من الشباب لعمل الخير حتى الئ يصل نفعه وفائدته للغير تطوعاً دون توقع لمردود مالي مقابل عمله.

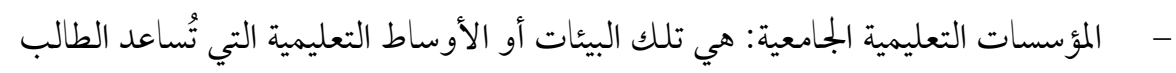

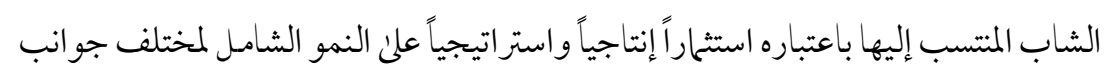


شخصيته، وإعداداه للتفاعل مع من حوله من الكائنات، والتكيف مع من حوله من مكونات، وتسعئ في ذلك بصورة عامة إلى الحثث علن العمل والتنمية بصورة شمولية في كافة الته

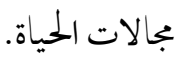

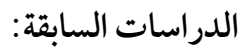
تعرض الدراسة فيا يلي بعضاً من الدّراسات والأبحاث السابقة المرتبطة بموضوع الدراسة

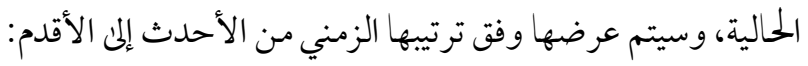
دراسة نصار (10 · ): هدفت للتعرف إلم دور كليات التربية في جامعات محافظات غزة في تنمية ثقافة العمل التطوعي لدئ طلبتهامن وجهة نظرهم، وقد كشفت النتائج أن دور كليات التربية

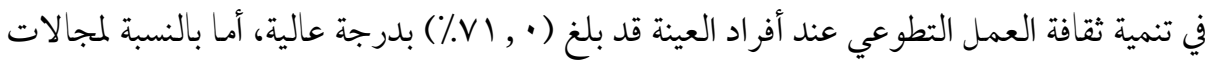

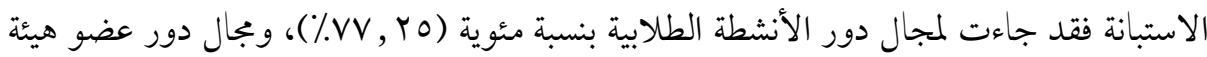

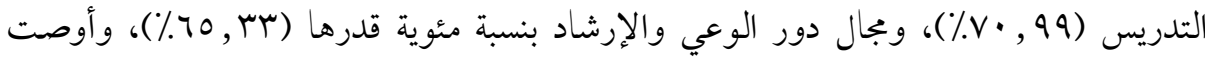

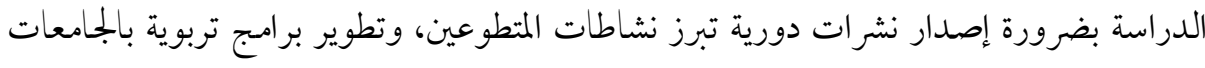
للتعريف بالعمل التطوعي، تكثيف المحاضرات والندوات والملتقيات ذات العلاقة بتنمية العمل التطوعي وضمان استمر اريته في سلوك الطلبة.

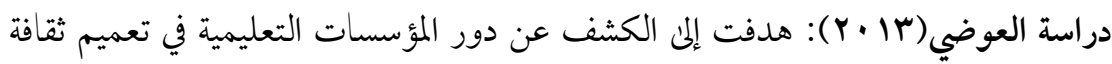

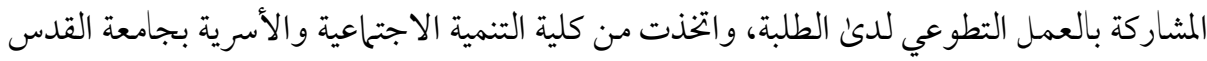

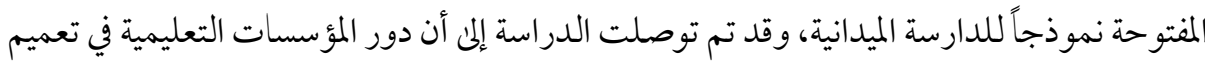

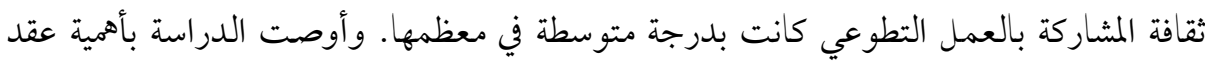

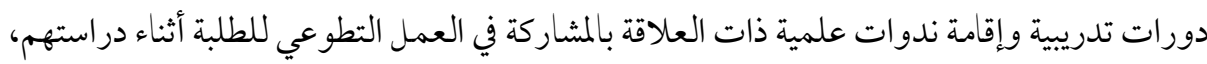
تشجيع مبادرات الشباب الجمعية التي تساهم في تطوير دورهم التطوعي والاشراف على عليها.

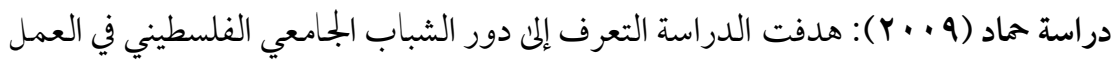
التطوعي في المؤسسات الفلسطينية، وسعت الدراسة إلى إبراز دور العمل التطوعي في خدمة المجتمع، 
وإبراز التجارب الوطنية والعربية والعالمية في هذا المجال، وأوصت الدراسة بالتأكيد علن أهمية تقديم المشورة للر اغبين في التطوع بما يناسب استعداداتهم وقدر اتهم وميو لهم من أعحال تطوعية، وكذلك تقديم المشورة لمختلف المؤسسات فيما يتعلق بخطط التدريب والإشراف، والتنسيق بين رغبات المتطوعين واحتياجات هذه المؤسسات العامة للجهود التطوعي.

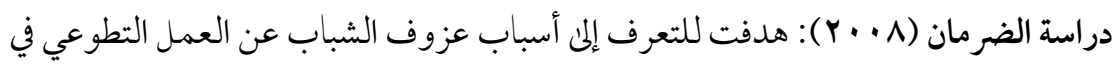
الجهات الخيرية بمنطقة الباحة، وتمثل مجتمع الدراسة من القائمين على الجهات الخيرية بالمنطقة، وقد وضع الباحث أربعة فروض، واستخدم المنهج الوصفي واستخدمت الدراسة أداة الاستبيان، وكان من أهم توصيات الدراسة: تسهيل الإجراءات الرسمية أما الكوادر الشبابية لتنفيذ البرامج وعدم

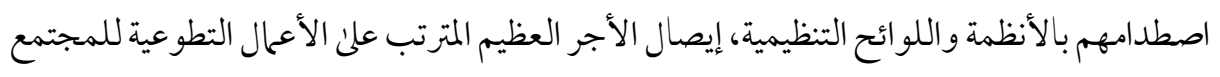

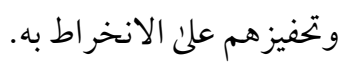

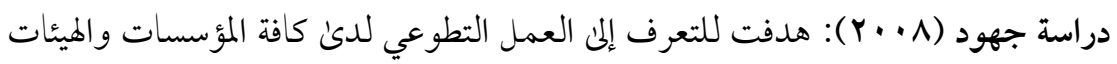
الحكومية والاهلية والخاصة، وشملت عينة الدراسة طلبة الجامعات، وأظهرت النتائج الدراسة: أن

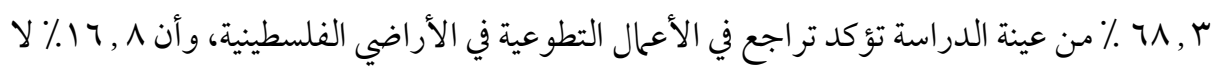
يدركون ادراك أهمية العمل التطوعي، و حمل V٪ المؤسسات الاهلية المسؤولية عن تراجع العمل التطوعي، وأعرب 0 , 91\% عن رغبتهم في التطوع في المؤسسات، وخلصت الدراسة إلى التأكيد علن ضرورة مبادرة المؤسسات بتوسيع دائرة العمل الطوعي، إلى جانب مو اجهة عو امل التراجع في العمل التطوعي.

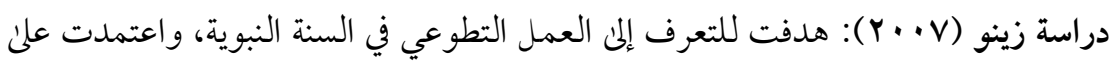

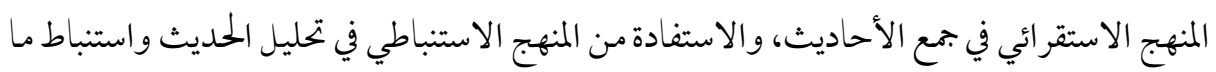
يفيد الموضوع، وكان من أهم توصيات الدراسة: لا بد من مشاركة المسئولين و القادة في العمل ليكونوا

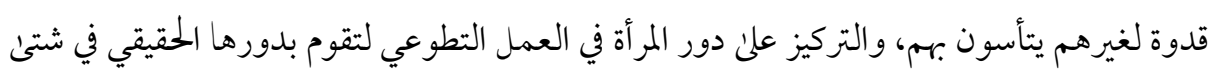


ججالات الحياة العلمية والاجتاعية والسياسية، وعلن المؤسسات الاهتحام بالعمل التطوعي كاهتحام المؤسسات في عهد النبي صلن الله علية وسلم.

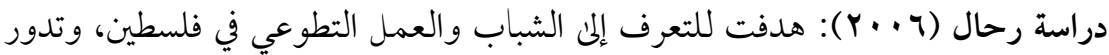
مشكلة الدراسة حول وجود قصور وخلل في عملية تعزيز وتفعيل العمل التطوعي في فلسطين، هذا إلن جانب قلة المشاركة الشبابية الفاعلة في الأعمال التطوعية، ويتجلن ذلك من خلال تلدني المشاركة ومحدوديتها في المجال العام، ويأتي في هذا الإطار عدم توفر المراكز التطوعية الكافية، وقلة الوعي بأهمية

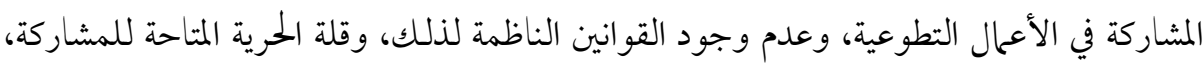
والعوائق الثقافية والاجتماعية والدينية، إلى جانب ضعف المنظمات غير الحكومية بهذا الجانب، وكان من أهم توصيات الدراسة: أهمية تفعيل وتطوير العمل التطوعي، ومشار كة فئات المجتمع المختلفة كلاً

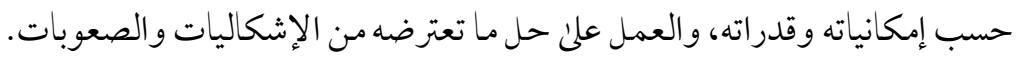

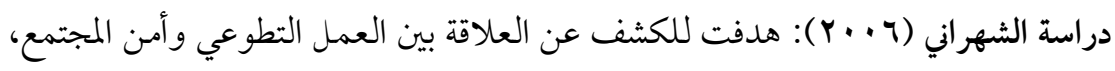
والتعرف إلنى خصائص المتطوعين ودوافعهم للالتحاق بالعمل التطوعي، وشملت الدراسة عينة قوامها

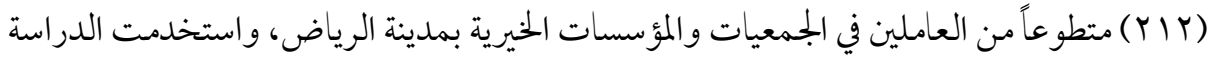

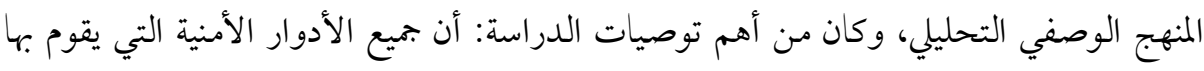

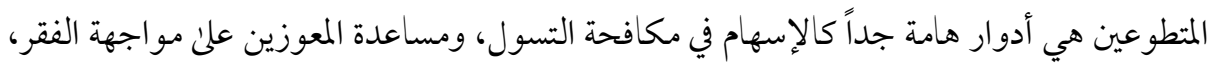
والإسهام في وقاية أسر وأطفال نز لاء السجون من التشرد والوقاية من الجريمة وأخطار المخدرات،

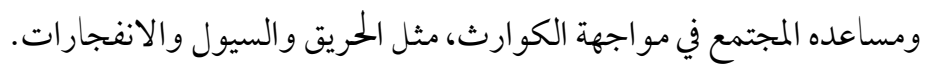

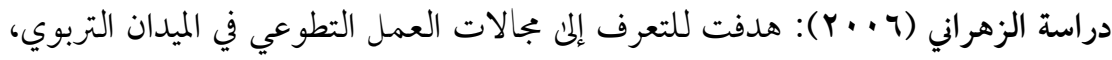

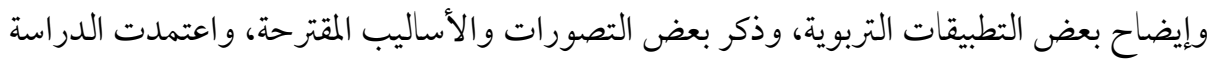

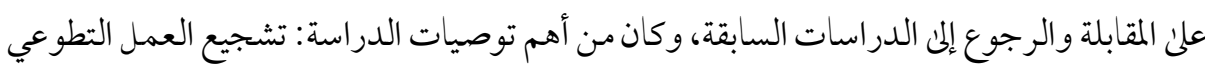

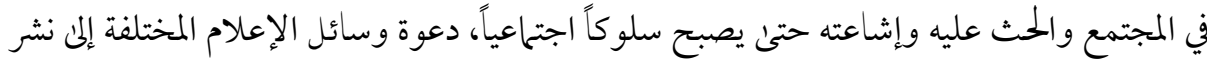
أدبيات العمل التطوعي في المجتمع وتعريف أفراده بأهمية العمل التطوعي. 
دراسة الزهراني (ع · · r): هدفت الدراسة للكشف عن دور العمل الخيري في تلبية الحاجات النفسية والاجتماعية والتربوية للشباب كما يراه العاملون في الجمعيات الخيرية، وتكونت عينة الدراسة من الشباب العاملين في الجمعيات الخيرية سواء كانوا موظفين برواتب أو كانو ا متسبين، وبلغ عددهم إجمالياً 90 شاباً، وقد قام الباحث بتصميم استبيان من هـ فقرة، وكان من أهم توصيات الدراسة: أن

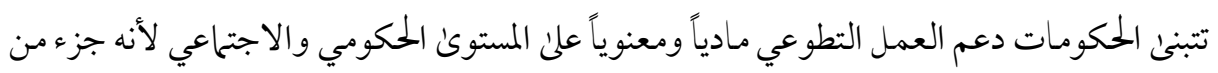
عقيدتنا الإسلامية.

دراسة الباز (Y + . r): هدفت الدراسة إلى معرفة مدئ مشاركة الشباب ورغبتهم في العمل التطوعي والعوامل المرتبطة بالتطوع من عوامل معوقات، والعوامل التي تؤثر في رغبة الشباب في المشاركة في العمل التطوعي، واستخدمت الدراسة المسح الاجتماعي لعينة من الشباب (سا ا ( ) مبحوثاً، وكان من أهم توصيات الدراسة: أن غالبية الشباب ليست لديهم مشاركة في العمل التطوعي، وعبر غالبية المبحوثين عن رغبتهم في المشاركة في العمل التطوعي وخدمة بجتمعهم، كما تطرقت الدراسة إلى معوقات العمل التطوعي، وكشفت الدراسة عن وجود علاقة بين المشاركة في العمل التطوعي ومتغير اكتساب الخبرة حيث أفاد بذلك ؟ 9 ٪ من المبحوثين، ودلت الدراسة إلى وجود علاقة قوية بين المشاركة في العمل التطوعي والرغبة في الحصول علن الأجر والثواب. دراسة الموسى (Y . . Y): هدفت الدراسة التعرف إلى ممارسة الفتاة السعودية للعمل التطوعي الدعوي، من خلال التعرف إلى الخلفية الشرعية للمبحوثات، والتعرف إلى معوقات هذه الممارسة وأثر الحالة الاجتماعية للطالبات علن ذلك، واستخدمت الدراسة المنهج الوصفي، ومجتمع الدراسة هو طالبات جامعة الملك سعود، و كان من أهم توصيات الدراسة: أن معوقات ممارسة المبحوثات للعمل التطوعي الدعوي تشكل مؤشرًا سلبيًا مرتفعًا، وأن المكانة الاجتهاعية للداعية تمنح القبول بين الناس، وأن الأسرة الممتدة تشجع على ممارسة العمل التطوعي. 


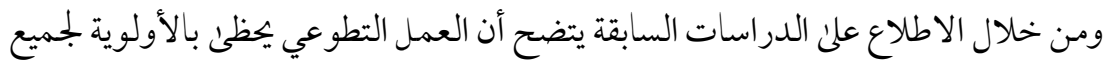
المجتمعات خصوصًا من حيث ارتباطه بحاجات وثقافات المجتمعات المختلفة وضمن اهتحام ومشاركة كافة شرائح المجتمع علن العمل التطوعي حيث يعد من الأعال الجليلة التي تظهر آثارها

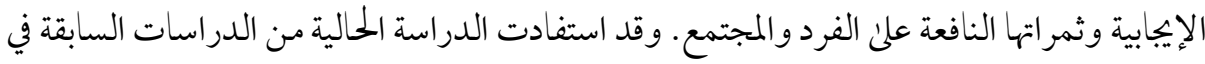
صياغة مشكلة الدراسة، وتحديد قائمة بمتطلبات وبجالات العمل التطوعي، وتميزت الدراسة الحالية

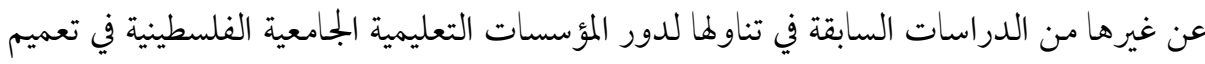
ثقافة المشاركة بالعمل التطوعي لدني الشباب، وتقديم سيناريوهات مقترحة لتطوير هذا الدور.

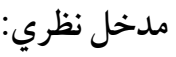

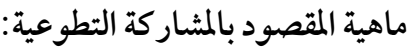
تعد المشاركة التطوعية نوع من المبادرة الإنسانية، وممارسة ايجابية نعيشها في الحياة اليومية،

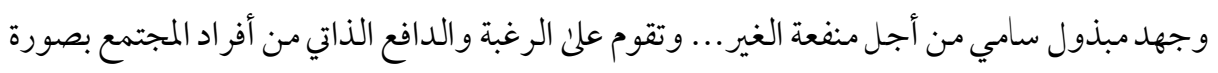

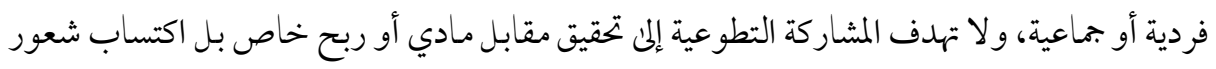

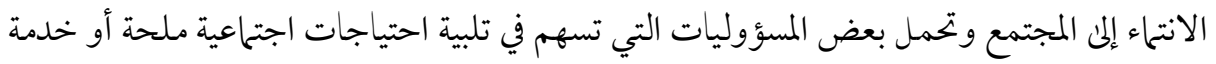

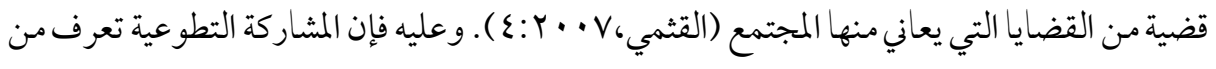

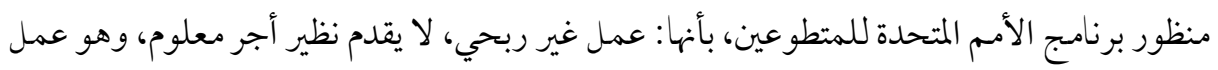

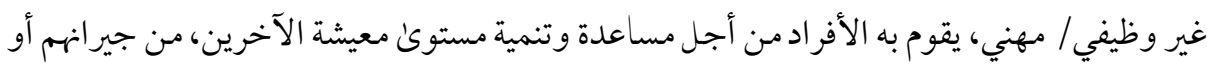

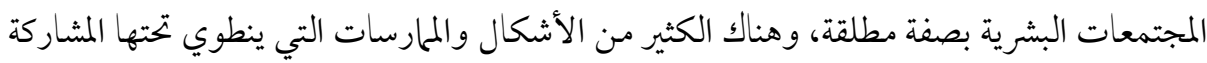

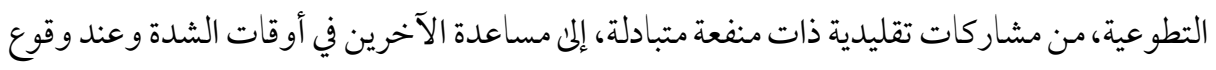
الكوارث الطبيعية والاجتماعية وإنما تمارس كرد فعل طبيعي دون توقع نظير مادي لذلك العمل

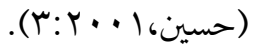

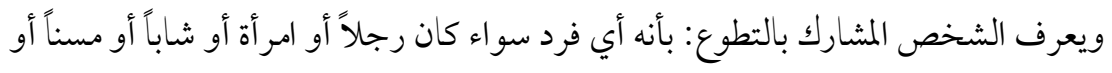

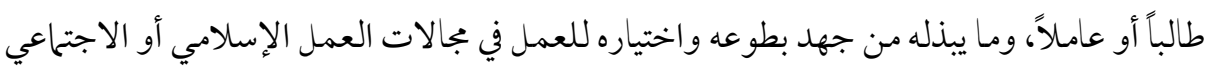


مستهدفاً من وراء ذلك صيانة أرواح وممتلكات المواطنين وثروة المجتمع الإسلامي والمسلمين ابتغاء

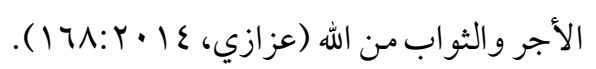

وتعرف المشاركة التطوعية أيضاً علن أنها التبرع بالجهد أو المال أو الوقت أو كلاهما معاً، للقيام

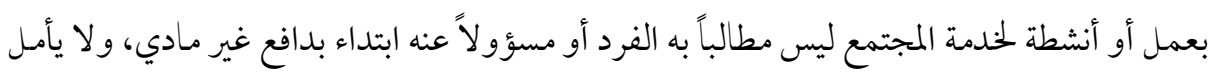

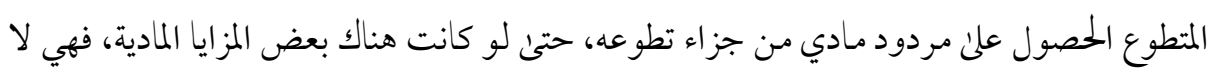

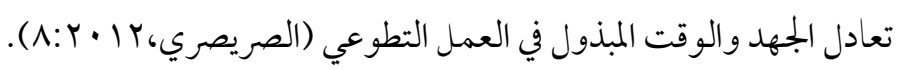
من خلال عرض التعريفات السابقة يتضح أن المشاركة التطوعية هي أي عمل يقوم به فرد أو ججموعة من الأفراد، الغاية منه تقديم الخدمة والمشورة والرعاية الفكرية أو أي شكل من أشكال الخدمات التي يقدمها للآخرين دون انتظار أي مردودمادي أو مكافآت، وهو عمل سام ورائع ومميز

$$
\text { يسمو به الإنسان ويرتقي.. }
$$

و المجتمع الفلسطيني من المجتمعات الإنسانية التي تتأصل به المشاركة التطوعية، والذي كانت تأخذ أشكالاً متعددة لعل أبرزها ما كانت تعرف في السابق (بالعونة) أو (بالمعونة) أو ( بالمساعدة) إلى أن اصطلح علن التسمية حديثًا بالتطوع، وقد كانت أشكال العونة ولاحقًا المشاركة التطوعية تأحذ

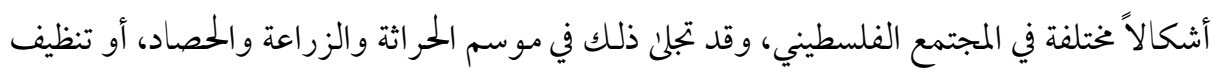

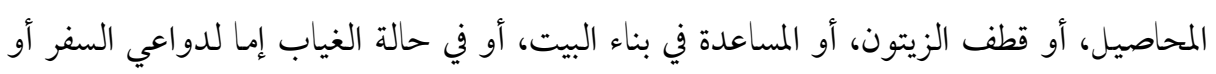
العسكرية أو السجن أو الملاحقة أو في أوقات الشدة مثل الموت أو الكوارث الطبيعية أو حالات الخسائر

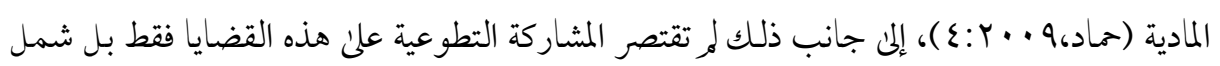

$$
\text { أيضًا الأفراح و الأعراس التي كانت تمتد إلى أيام عدة. }
$$

من هنا يمكن القول أن المشاركة التطوعية في المجتمع الفلسطيني تأخذ أشكال وأبعاد وطبيعة خختلفة حسب اللحظة التاريخية، وبالتالي فإن تفعيل وتعزيز المشار كة التطوعية في مجتمعنا تتطلب في المقام الأول ضرورة إحداث تغيير في الوعي المجتمعي من أجل تفعيل وتطوير ونشر ثقافة المشاركة التطوعية بين الشباب الجامعي، ويكون ذلك من خلال استخدام كافة وسائل إحداث التغيير والتي قد تكون علن 
شكل برامج تنمية اجتحاعية، من خلال المؤسسات التعليمية المختلفة، ودوائر العلاقات العامة بها، وعمادة شئون الطلبة، وتقديم المطبوعات الثقافية التوعوية حول المشاركة التطوعية، واستطلاعات

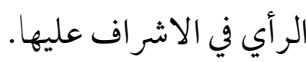

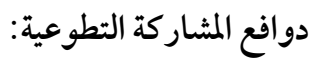
كثيرة هي العوامل التي تدفع الإنسان إلى التطوع ولعل أهمها: ا ـ. التطوع من أجل حب الآخرين وتقديم المساعدة لهم. r. التطوع من اجل تكوين العلاقات الاجتماعية واستثمارها. r. التطوع من أجل اكتساب مهارات وخبرات جديدة قد يحتاجها المتطوع مستقبلاً في حياته العملية قد لا تتوفر له إلا من خلال مر اكز التطوع (نصار، 0 ( ب : 7 )

$$
\begin{aligned}
& \text { ع. ـ العمل من أجل الصالح العام. } \\
& \text { ه. حب العمل مع الآخرين. }
\end{aligned}
$$

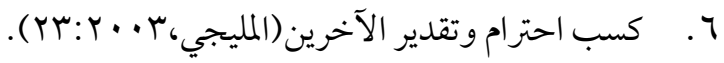

وتتعدد الدوافع والأسباب للانضمام للعمل التطوعي وتتشابك وتتقاطع، وليس بالضرورة أن يكون الدافع للعمل التطوعي واحداً، بل في الغالب تتعدد وتتأثر ببعضها بصور متفاوتة... ففي الدراسات التي أجريت في أمريكا يمثل دافع مساعدة الآخرين س\%٪ وهو أكثر الدوافع، يليه دافع

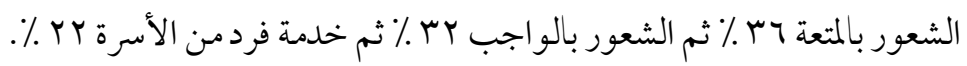

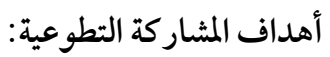

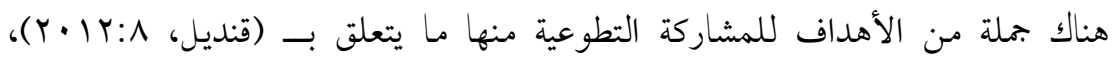

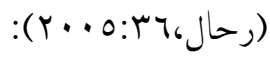
أولاً: بالمجتمع: - - الحد من المشاكل الاجتماعية ووضع الحلول ها. - عريف المجتمع بالظروف الحقيقية لمجتمعهم. 


\section{- - تعريف أفراد المجتمع بالفئات الأكثر تهميشاً وحرماناً بالمجتمع . - - الوصول إلى تفاهم والتفاف حول الأعمال التطوعية.}

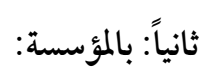

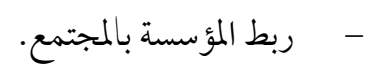

- استثمار الكفاءات والخبرات الكامنة لدئ المتطوعين وتفعيلها.

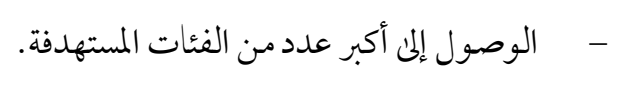
ثالثاً: أهداف خاصة بالمتطوعين:

$$
\text { - - - استثمار وقت الفراغ بطريقة حرة وشرعية. }
$$

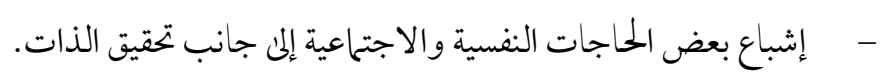

ويرىن الباحث أن المشاركة التطوعية نابعه عن أهداف متنوعة يسعى القائمين والداعين المه

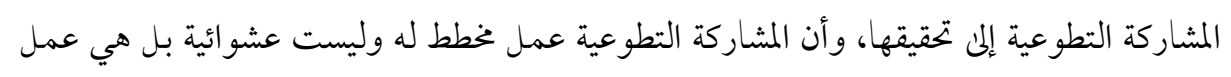

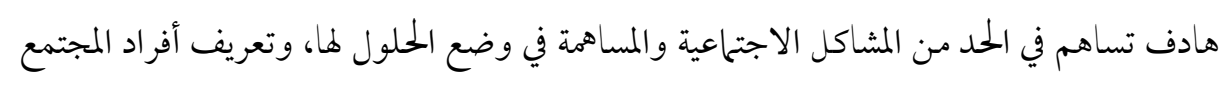
بالظروف الحقيقية لمجتمعهم وإشر اكهم في وضع البرامج والأنشطة وتنفيذها والمشاركة في التقييم وصو لاً إلى الو اقعية في المطالب.

\section{أهمية مشار كة الشباب في الأعمال التطوعية: - مات}

يترتب على ممارسة المشاركة التطوعية جملة من الآثار الايجابية التي تعود علن الشباب المتطوعين

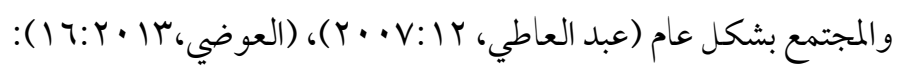

$$
\begin{aligned}
& \text { 1. . الشعور بالر احة النفسية عند القيام بالمشاركة التطوعية. } \\
& \text { r. الشعور بتحقيق مكسب ديني وهو الأجر والثواب من الله. } \\
& \text { r. الشعور بأهمية الترابط بين أفراد المجتمع فيسعى إلمان المشاركة. } \\
& \text { ع. زيادة وتقوية الانتحاء الوطني بين الشباب. }
\end{aligned}
$$


0. القضاء علن أوقات الفراغ ووجودما يشغل ذلك الفراغ. T. . زيادة الإحساس بذات الشباب الفلسطيني وأهميته في المجتمع.

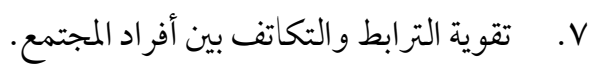

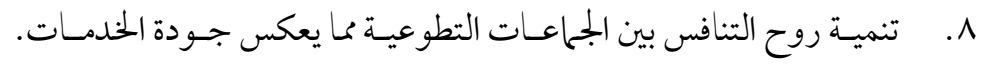

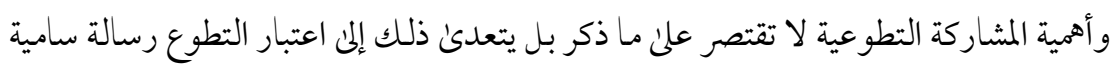
وعظيمة يؤديها الشاب المتطوع لخدمة جتمعله وتقديم جزء من وقته وجهده في سبيل مجتمعه وحينها

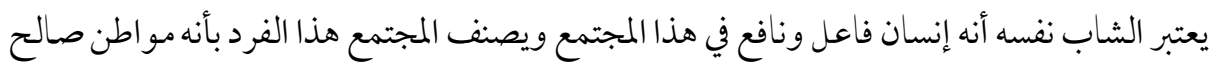

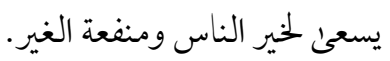

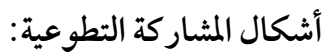
يمكن التمييز بين شكلين أساسيين من أشكال المشاركة التطوعية، (الزهراني، ع . ب ؟ ه ):

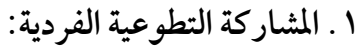
وهي سلوك اجتماعي يارسه الفردمن تلقاء نفسه وبرغبة منه وإرادة ولا يبغي منه أي مردود مادي، وتقوم علن اعتبارات أخلاقية أو اجتماعية أو إنسانية أو دينية.

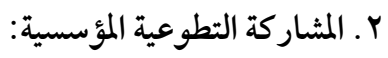
وهي أكثر تقدماً من المثاركة التطوعية الفردي وأكثر تنظياً وأوسع تأثيراً في المجتمع، وفي تلثيات

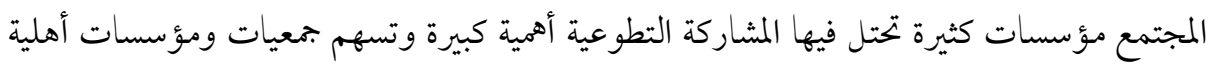

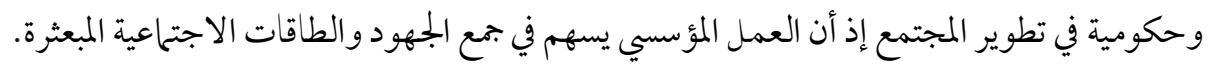

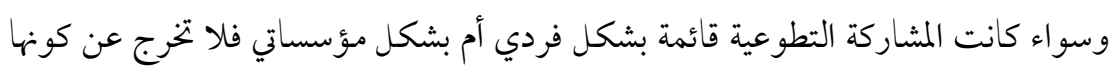

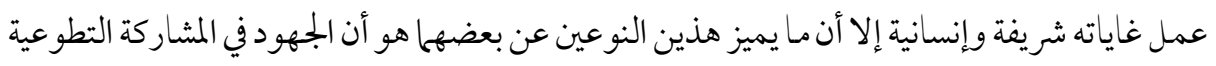

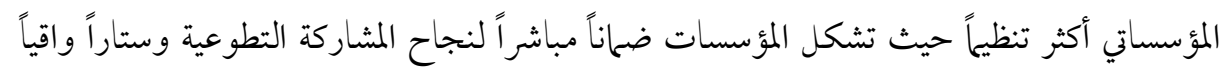
للمتطوعين. 
دور المؤسسات التعليمية الجامعية الفلسطينية في تنمية قيم المشاركة التطوعية: تعتبر المؤسسات داخل أي بجتمع وضمن أي نظام اجتماعي هي الأداة القادرة على إحداث التغيير المرغوب الذي يطمح المجتمع في تحقيقه وغرسه في نفوس أبنائه، حيث تعتبر هذه المؤسسات

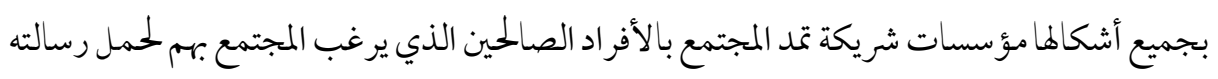

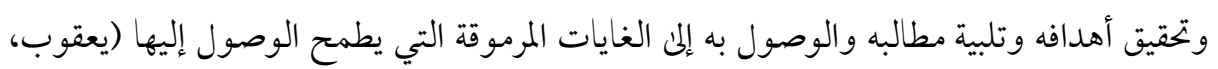

(I Y:Y...O

ولعل من أهم ما يطمح المجتمع في الشاب هو أن يكون مواطن وانسان صالح ونافع وخادم

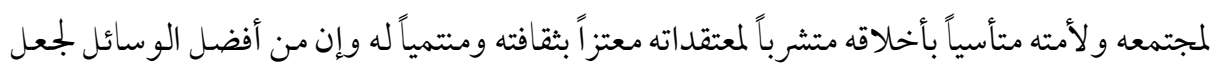
أبناء المجتمع مو اطنين صالحين ونافعين هي مشاركتهم في خدمة بجتمعهم من خلال العمل التطوعي. حيث يقع علن عاتق المؤسسات التعليمية تنمية قيم التطوع لدئ الشباب بكافة الوسائل وعبر كل الطرق التي من شأنها غرس قيم المشاركة في العمل التطوعي في نفوس الشباب والتي من أهمها دورها التوعوي والاشرافي علن ممارسات الشباب داخل المؤسسات الخيرية الخدماتية (العبد، $(7: Y \cdot 1 r$ ومن القواعد العلمية أنه كلما زادت حركة المشاركة في حقل التطوع في مجتمع ما كلما زادت حركة البناء والرقي وتحقق الأمن والتكافل في المجتمع... ويأتي هذا بتشجيع المشاركة بالعمل التطوعي والحث علن إشاعته حتى يصبح سلوكاً اجتماعياً، ويحدث هذا من خلال دعوة المؤسسات المختلفة إلى نشر أو بيان العمل التطوعي، وحث مر اكز البحوث والمؤسسات الخيرية والجامعات والمعاهد علن إعداد البحوث والدراسات النظرية والميدانية في مجال العمل الخيري... وتوسيع الأعال التطوعية ومراعاة

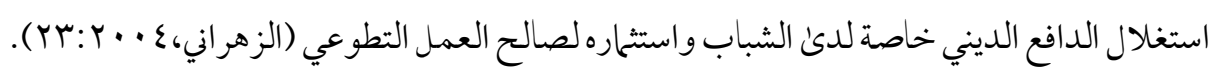
وتعتبر المؤسسة التعليمية الجامعية الفلسطينية من المؤسسات التي تعد وتنمية وترعنى وتؤثر في الشباب، حيث أنها تهدف في المقام الأول إلى العناية بالشباب اجتماعياً وتعليمياً وتربوياً وتنمية قدراتهم وإمكانياتهم وبناء قدراتهم وتمكينهم، علن اعتبار أنهم أمل الغد، إلى جانب تنظيم هذه المؤسسات 
للفعاليات المختلفة سواء كانت رياضية أو فنية أو ثقافية أو توعويه تثقيفية كجزء من أولوياتها و اهتماماتها الموجهة للشباب بغية تطويرهم نحو الأفضل كما تراعئ هذه المؤسسات إشاعة روح العمل الجماعي و التطوعي، وغرس القيم الإيجابية عند الشباب من جهة، ومن جهة ثانية تحميهم من الأفكار السلبية كالطائفية والفئوية والعنصرية والحيوية، إلى جانب محاربتها للعادات والتقاليد البالية، وإحلال مكانها العادات والتقاليد التي تنسجم مع التراث الحضاري لمجتمعهم. منهج البحث: يعتمد البحث علئ المنهج الوصفي التحليلي؛ للتعرف إلى دور المؤسسات التعليمية الجامعية في تعزيز قيم مشاركة الشباب الفلسطيني في العمل التطوعي من وجهة نظرهم، كما تم استخدام الأسلوب الاستشر افي لوضع السيناريوهات المقترحة. مجتمع البحث: بناءً علن مشكلة البحث وأهدافه فإن بجتمع الدراسة تكون من جميع الشباب الفلسطيني في المؤسسات التعليمية الجحامعية في محافظات غزة والمشاركين ببرامج وأنشطة المؤسسات المحلية. عينة البحث: أجري البحث على عينة قوامها (rr/) مبحوثاً من الشباب الذين لديهم أنشطة اجتماعية في المؤسسات التعليمية الجمامعية في محافظات غزة، وهي: (شمال غزة، غزة، الوسطى، خانيونس، رفح)، حيث تمثل المحافظات الطبقات التي تم اختيار العينة منها. والجدول التالي يبين وصف عينة البحث تبعاً للمتغيرات المستقلة.

$$
\text { جدول رقم (1): توزيع عينة البحث الميدانية }
$$

\begin{tabular}{|c|c|c|c|}
\hline النسبة المئوية & التكرار & المتغيرات & البيان \\
\hline$\%$ \% , $\varepsilon$ & $\varepsilon r v$ & ذكور & \multirow{2}{*}{ الجنس } \\
\hline$\% \varepsilon V, T$ & rat & إناث & \\
\hline
\end{tabular}




\begin{tabular}{|c|c|c|c|}
\hline النسبة المئوية & 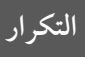 & المتغيرات & 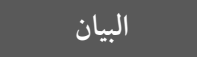 \\
\hline$\% r \mid, r$ & $I V \wedge$ & المستوى الأول & \multirow{4}{*}{ المستوئ التعليمي } \\
\hline$\%$ \%r, r & 519 & المستوكئ الثاني والثالث & \\
\hline$\% \varepsilon 1,1$ & $r \varepsilon r$ & المستوئ الرابع & \\
\hline$\% 11, r$ & 94 & دراسات عليا & \\
\hline$\% \pi 1, r$ & 011 & من 19-0مr & \multirow{3}{*}{ الفئات العمرية } \\
\hline$\% r \wedge, r$ & rro & من Or-100 & \\
\hline$\% \cdot, \varepsilon$ & $\wedge \vee$ & من 00 عام فأكثر & \\
\hline $1 \cdots$ & ( ) & \multicolumn{2}{|c|}{ الإجمالي } \\
\hline
\end{tabular}

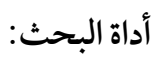

قام الباحث بإعداد استبانة للوقوف علن دور المؤسسات التعليمية الجلمعية في تعزيز قيم مشاركة الشباب الفلسطيني في العمل التطوعي من وجهة نظرهم، حسب الخطوات التالية:

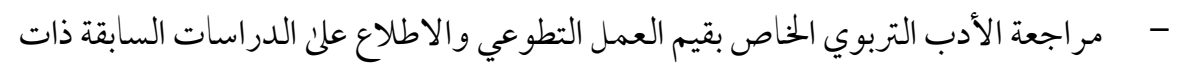

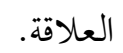
- تحديد بجالات الأداة وهي: (تعزيز ثقافة قيم العمل التطوعي، الوعي والإرشاد لقيم العمل

$$
\text { التطوعي، الإشر اف علن قيم العمل التطوعي). }
$$

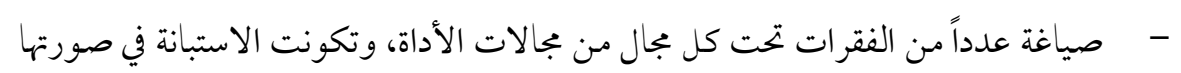

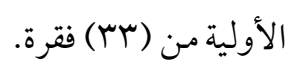

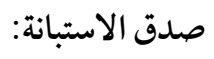

$$
\text { تم التأكد من صدق الاستبانة عن طريق: الت }
$$

أ. صدق المحكِّمين: تم عرض الاستبانة على عدد من المحكمين من ذوي الاختصاص من صن فريق

أساتذة الجامعات الفلسطينية في محافظة غزة، وممن لديهم اهتحام بالعمل التطوعي، وحقوق الإنسان و التربية والمدنية والخبرة في مؤسسات المجتمع المدني، وقد طُلب منهم إبداء ملاحظاتهم حول صلاحية 
الاستبانة للهدف الذي وضعت لأجله، ومدئ مناسبة الفقرات لكل مجال، ومدئ الدقة العلمية و اللغوية، واقتراح ما يرونه مناسباً.

وفي ضوء ما ورد من ملاحظات تم إضافة بعض الفقرات، ودمج البعض الآخر، وحذف

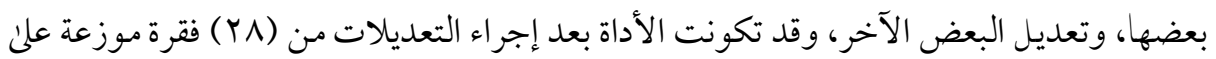

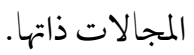

صدق الاتساق الداخلي: تم التأكدمن صدق الاتساق الداخلي بحساب معاملات ب ارتباط بيرسون بين درجات كل مجال من المجالات والدرجة الكلية للاستبانة بالتطبيق على العينة الاستطلاعية، وذاك لإيجادمعاملات الارتباط لكل فقرة بالمجال الذي تنتمي إليه، ومعاملات الارتباط بين كل مجال و الدرجة الكلية، وتبين أن قيمة الارتباط في هذه الدراسة بلغت (^^ , • )، للاستبيان ككل وهو ارتباط عال يشير إلى صلاحية الاستبانة.

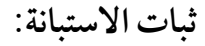

للتحقق من ثبات أداة الدراسة، تم استخراج معاملات الثبات حسب معادلة ألفا كرونباخ alpha Cronbach coefficient و والتي تعتمد على الاتساق في أداء الفرد من فقرة إلى أخرىن، وتستند إلى الانحراف المعياري للاختبار والانحرافات المعيارية للفقرات مفردة، وكانت النتائج كما في

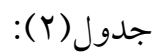

جدول رقم (Y) - معاملات الثبات لأداة الدراسة

\begin{tabular}{|c|c|c|}
\hline معامل ألفا & 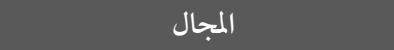 & 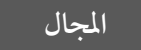 \\
\hline$\cdot, \wedge \varepsilon$ & تعزيز ثقافة قيم العمل التطوعي & المجال الأول \\
\hline$\cdot, \wedge r$ & الوعي و الإرشاد لقيم العمل التطوعي & المجال الثاني \\
\hline$\cdot, \wedge 7$ & الإشر اف علن قيم العمل التطوعي & المجال الثالث \\
\hline$\cdot, \wedge \varepsilon$ & \multicolumn{2}{|c|}{ الثبات الكلي للاستبانة } \\
\hline
\end{tabular}

http://dx.doi.org/10.29009/ijres.4.3.6 
يتضح من الجدول السابق أن معاملات ارتباط كل مجال من المجالات، والدرجة الكلية للاستبانة جميعها كانت مرتفعة، مما يدل علن أن الاستبانة تتمتع بدرجة عالية من الصدق مقبولة لأغراض الدراسة الحالية.

المحك المعتمد في الدراسة: اعتمدت الدراسة على مقياس ليكرت الخحاسي التدريج كمحك للدراسة، والذي يتضمن الاستجابات من خمسة اختيارات هي: (كبيرة جداً، كبيرة، متوسطة، قليلة،

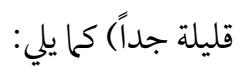
جدول رقم (ץ): مقياس ليكرت والمحك المعتمد

\begin{tabular}{|c|c|c|c|c|c|}
\hline قليلة جداً & قليلة & متوسطة & كبيرة & كبيرة جداً & مستوى الموافقة \\
\hline $1, \wedge-1$ & $r, r-1, \wedge$ & $r, \varepsilon-r, \tau$ & $\varepsilon, r-r, \varepsilon$ & $0-\varepsilon, r$ & الوسط الحسابي \\
\hline 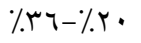 & \% & $\%$ \% A-\% \% & $\% . \wedge \varepsilon-\%$ \% & $\% 1 \cdots-\% \varepsilon$ & النسبة المئوية \\
\hline
\end{tabular}

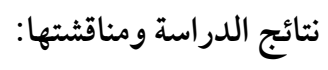
النتائج المتعلقة بالإجابة عن السؤال الأول ونصه: ما دور المؤسسات التعليمية الجامعية في تعزيز ثقافة قيم المثار كة بالعمل التطوعي لدى الشباب الفلسطيني من وجهة نظرهم؟

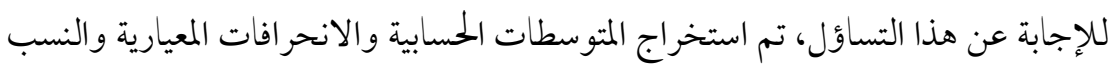
المئوية، لكل فقرة من فقرات بجال تعزيز ثقافة قيم المشاركة بالعمل التطوعي، كما هو موضح بالجدول التلي: جدول رقم (ع) : نتائج بجال تعزيز ثقافة قيم المشاركة بالعمل التطوعي مرتَّة تنازليًا

\begin{tabular}{|c|c|c|c|c|c|}
\hline التقدير & 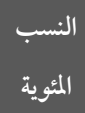 & المعياري - المراف & المسابي & الفقرات & تر تيبها \\
\hline كبيرة جداً & $\wedge \uparrow, \wedge$ & $1, \cdot 9$ & 4.34 & تعقافة العمل المؤسسات التعليمية الجامعية علن تعزيز & 1 \\
\hline كبيرة جداً & $10, \wedge$ & $1, \cdot r$ & 4.29 & توجه المؤسسات التعليمية الجامعية الشباب نحو & $r$ \\
\hline
\end{tabular}




\begin{tabular}{|c|c|c|c|c|c|}
\hline التقدير & 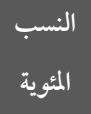 & 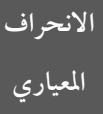 & المتوسط & الفقرات & ترتيبها \\
\hline كبيرة & $V Y, \wedge$ & 1.30 & 3.64 & تقدم المؤسسات التعليمية أفكار تحث على الأعمال & $v$ \\
\hline كبيرة & $7 \wedge, \cdot$ & $1, \cdot 1$ & 3.40 & الإلجهود نحو القيام بالأعمال التطوعية بالتعلية الجامعية الشباب في & $\wedge$ \\
\hline متوسطة & TV, T & $1, \cdots$ & 3.38 & و تحترم المؤسسات التعليمية الجامعية أعمال الشباب & $\varepsilon$ \\
\hline متوسطة & $\pi r, \Lambda$ & 1.21 & 3.14 & تحث المؤسسات التعليمية الجحامعية الشباب على الجمل & 1 \\
\hline متوسطة & $\pi r, r$ & 1.29 & 3.11 & تعمل المؤسسات التعليمية الجامعية على تكوين & $r$ \\
\hline متوسطة & $71, \wedge$ & $1, \cdot r$ & 3.09 & 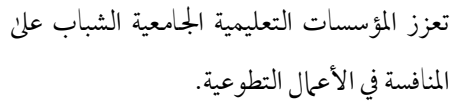 & 0 \\
\hline كبيرة & $V \cdot, ৭ ৭$ & $1, \cdot 1$ & $r, 0\}$ & الدرجة الكلية & \\
\hline
\end{tabular}

$$
\text { يتضِّح من نتائج الجلدول رقم (ع) ما يلي: }
$$

- أنَّ الدرجة الكلية لمتوسطات بجال دور تعزيز ثقافة قيم المشاركة بالعمل التطوعي كما يراها

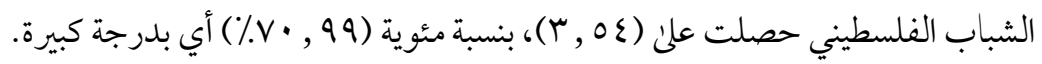
- كانت أعلى المتوسطات من نصيب الفقرة رقم (7) التي تنص علن" تعمل المؤسسات التعليمية

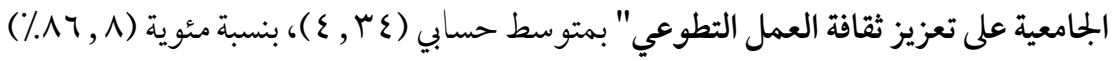
بدرجة كبيرة جداً. ويعزو الباحث ذلك إلى حرص المؤسسات التعليمية الفلسطينية على ثقافة الشباب وربط ذلك بقيم العمل التطوعي، وتطابق سلوك الشباب مع الأفعال والحرص علن اكتساب الخبرات الإيجابية في أنشطة المجتمع التطوعية. 
- وجاءت الفقرة رقم (r) في المرتبة الثانية والتي تنص علن" توجه المؤسسات التعليمية الجامعية

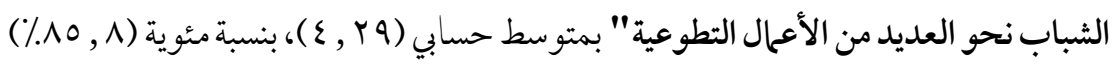
بدرجة كبيرة جداً. ويعزو الباحث ذلك إلى حث المؤسسات التعليمية الفلسطينة الشباب على لئ المشاركات التطوعية في الفعاليات الوطنية والأعمال الاجتماعية، وتوظيف التعاون بين الشباب

$$
\text { و العمل كروح الفريق. }
$$

- و كانت من أدنئ المتوسطات من نصيب الفقرة رقم (r) في المرتبة قبل الأخيرة و التي تنص علني" تعمل المؤسسات التعليمية الجامعية على تكوين علاقات بالمؤسسات الاجتحاعية لتسهيل

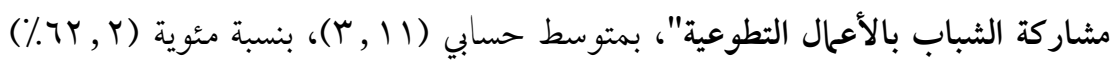
بدرجة متو سطة. ويعزو الباحث ذلك إلى أدوار المؤسسة التعليمية المتعددة على كافة أنشطتها التربوية والتعليمية والاجتماعية، بالإضافة إلى قلة تبني برامج أو مشاريع أو أعمال تكون بحاجة إلى الأعمال التطوعية والمبادرات الشبابية. - وفي المرتبة الأخيرة جاءت الفقرة رقم (0) و التي تنص علن " تعزز المؤسسات التعليمية الجامعية

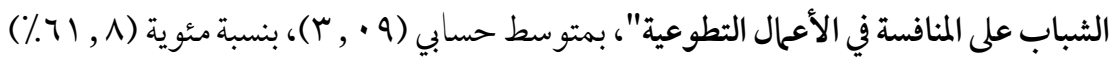
بدرجة متوسطة. ويعزو الباحث ذلك لقلة اهتمام ومتابعة بعض قادة المؤسسات التعليمية بالأعمال التطوعية وتعزيزها لإعطاء الأولوية للعملية التعليمية. وبشكل عام يرى الباحث أن هناك مبادرات مؤسساتية في المجتمع الفلسطيني في تعزيز ثقافة قيم المشاركة بالعمل التطوعي لدئ الشباب، حيث الاهتمام بنشر ثقافة قيم المشاركة بالعمل

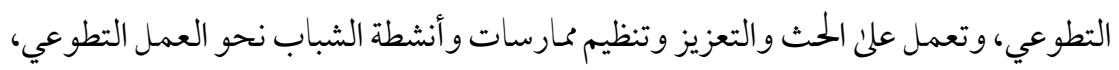
و العمل على تزويد الشباب بمعلومات إضافية حول تثقيف قيم العمل التطوعي لديهم، ومناقشة أفكار ومبادرات مع الشباب في ممارسة العمل التطوعي.

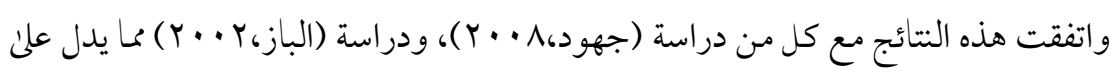
وجود جهد في تشجيع الشباب نحو العمل التطوعي؛ وتختلف مع دراسة الحازمي وآخرون (10 • (Y). 
التتائج المتعلقة بالإجابة عن السؤال الثاني ونصه: ما دور المؤسسات التعليمية الجامعية في تقديم الوعي والإرشاد لتعزيز قيم ثقافة المشاركة بالعمل التطوعي لدى الشباب الفلسطيني من وجهة نظرهم؟ للإجابة عن هذا التساؤل، تم استخراج المتوسطات الحسابية والانحرافات المعيارية والنسب المئوية، لكل فقرة من فقرات الاستبانة المتعلقة بالوعي والإرشاد لقيم العمل التطوعي. كما هو موضح

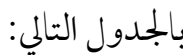

جدول رقم (0): نتائج ججال بالوعي والإرشادلقيم العمل التطوعي مرتَّة تنازليًا

\begin{tabular}{|c|c|c|c|c|c|}
\hline التقدير & 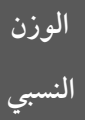 & الانحر اف المعياري & المستوسط & الفقرات & في ترتيبها \\
\hline كبيرة & 69.23 & 1.14 & 3.46 & تبين المؤسسات التعليمية الجامعية أهمية & r \\
\hline كبيرة & 68.84 & 1.12 & 3.44 & الفخر والاعتزاز للعمل التطوعسات التعليمية الجامعية مشاعر & 9 \\
\hline كبيرة & 68.22 & 1.04 & 3.41 & 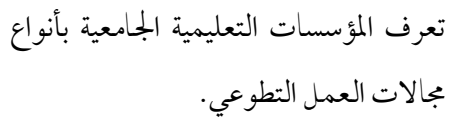 & $\varepsilon$ \\
\hline متوسطة & 67.85 & 1.09 & 3.39 & 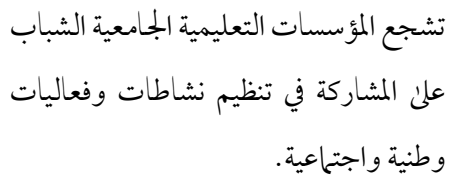 & 1 \\
\hline متوسطة & 67.6 & $1, \cdot 0$ & 3.38 & التعاون والألفة بين الشباب وكافة الأفراد. & 1 \\
\hline متوسطة & 67.4 & $1, \cdot r$ & 3.37 & 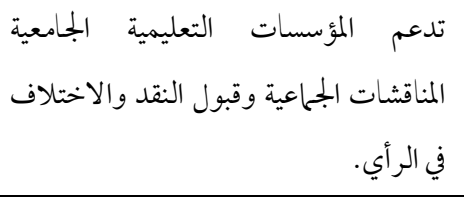 & $r$ \\
\hline متوسطة & 67.2 & 1.21 & 3.36 & 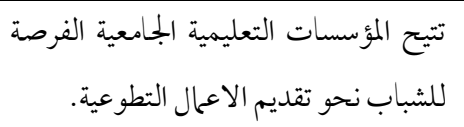 & 0 \\
\hline
\end{tabular}




\begin{tabular}{|c|c|c|c|c|c|}
\hline التقدير & 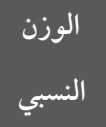 & 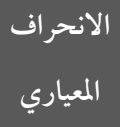 & المسابي - المبط & الفقرات & 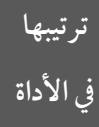 \\
\hline متوسطة & 57.0 & $1, \cdot 1$ & 2.85 & 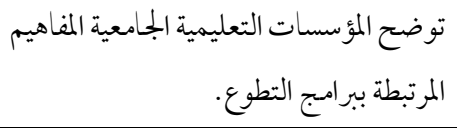 & $\wedge$ \\
\hline متوسطة & 54.8 & 1,11 & 2.74 & 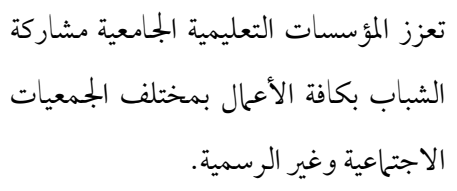 & $v$ \\
\hline متوسطة & To, rr & $1, \cdot 1$ & $r, r$ & الدرجة الكلية & \\
\hline
\end{tabular}

$$
\text { يتضّح من نتائج الجمدول رقم (0) ما يلي: }
$$

- - أنَّا لدرجة الكلية لمتوسطات مجال دور المؤسسات الفلسطينية في الوعي والإرشاد لقيم العمل

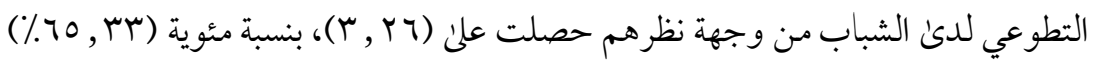

$$
\text { أي بدرجة متوسطة. }
$$

- كانت أعلن المتوسطات من نصيب الفقرة رقم (Y) التي تنص على" تبين المؤسسات التعليمية

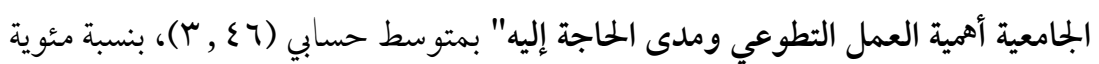

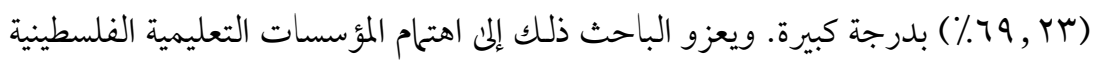
نحو إشباع حاجات الشباب المعرفية والمهارية والوجدانية والسلوكية بموضوع العمل التطوعي، وتزويدهم بمعلومات إضافية تنمي قيم العمل التطوعي لديهم وبعض الممارسات المرتبطة به كالعمل التعاوني والمشاركة والعمل بالفريق.

- جاءت الفقرة رقم (9) في المرتبة الثانية والتي تنص علن" تولد المؤسسات التعليمية الجحامعية مشاعر الفخر والاعتزاز للعمل التطوعي" بمتوسط حسابي (ع ع,؟)، بنسبة مئوية

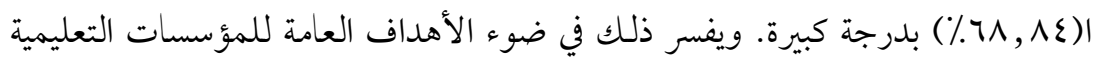
الفلسطينية في المحافظة علن الثقافة الوطنية الفلسطينية ضمن استراتيجياتها، والاعتزاز بأحد عناصرها كقيم العمل التطوعي، وذلك من خلال تنمية مشاركة الشباب في نشاطات وفعاليات وطنية والارتباط بقيم المواطنة.

http://dx.doi.org/10.29009/ijres.4.3.6 
- وكانت من أدني المتوسطات من نصيب الفقرة رقم (^) في المرتبة قبل الأخيرة والتي تنص

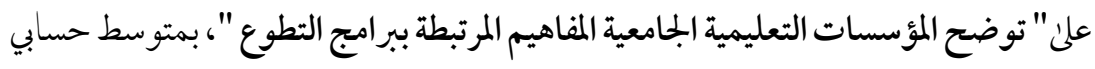

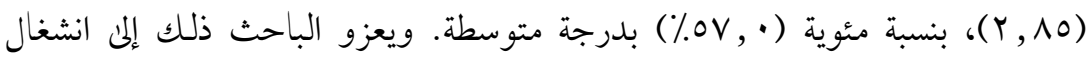
المؤسسات التعليمية عن تضمين القيم المرتبطة بالعمل التطوعي كالروح الجماعية والالتزام

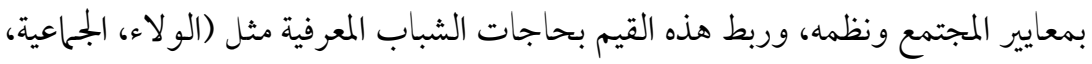

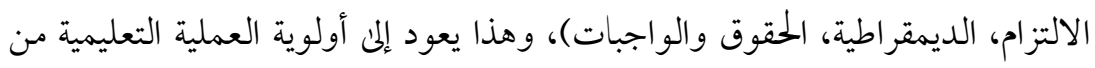

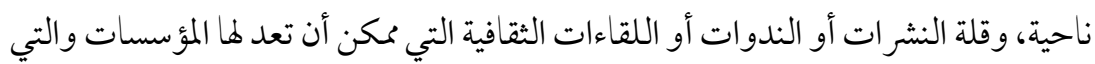
تنمي ثقافة الشباب نحو العمل التطوعي من ناحية أخرىن.

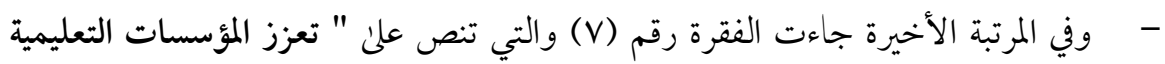

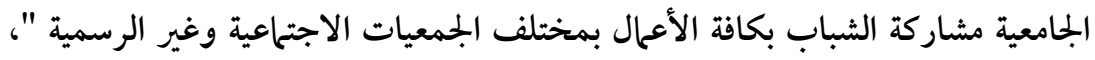

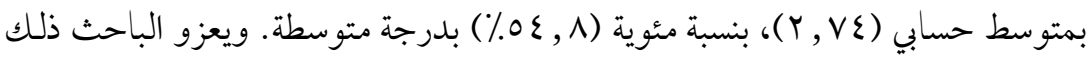

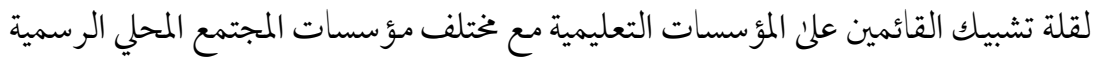

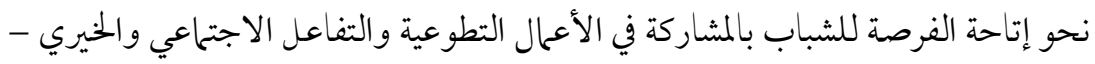
يعتبر البعض أن هذا ليس من ضمن أهدافها وأدوارها.

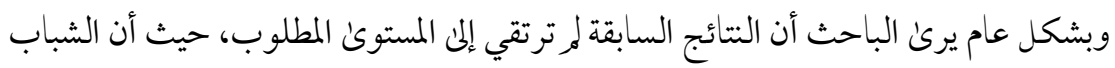
لا يروا في دور المؤسسات التعليمية الجامعية الفلسطينية في الوعي والإرشاد لقيم العمل التطوعي

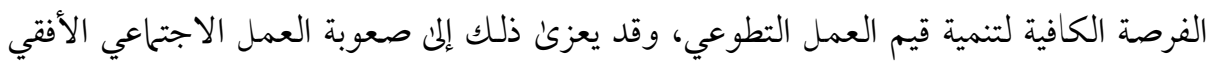

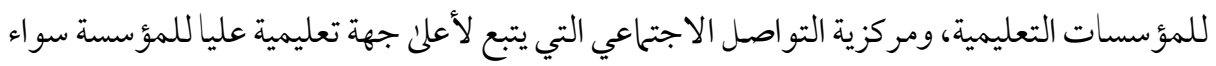

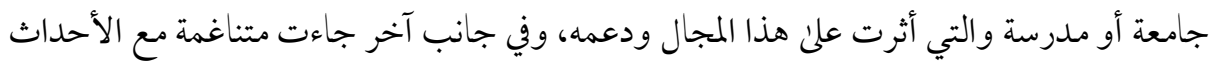

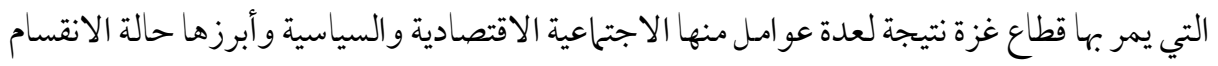
السياسي بين قطاع غزة والضفة الغربية. 
واتفقت هذه النتائج مع كل من دراسة الحازمي وآخرون (Y (Y))، ودراسة (ضرمان،

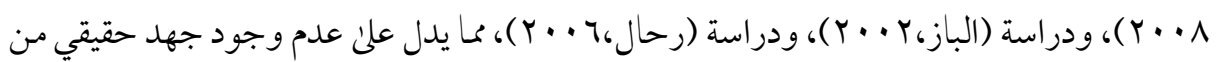
قبل المسؤولين للعمل التطوعي؛ وتختلف مع دراسة Corporation for National and Community

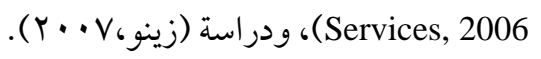

النتائج المتعلقة بالإجابة عن السؤال الثالث ونصه: ما دور المؤسسات التعليمية الجامعية في الإشراف

$$
\text { على قيم المشار كة بالعمل التطوعي لدى الشباب الفلسطيني من وجهة نظرهم؟ }
$$

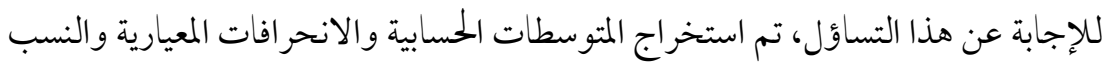

المئوية، لكل فقرة من فقرات الاستبانة المتعلقة بالإشراف علن قيم العمل التطوعي. كما هو موضح

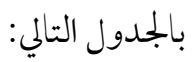

\begin{tabular}{|c|c|c|c|c|c|}
\hline التقدير & 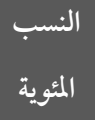 & المعياري & المستوسط & الفقرات & في ترتيها \\
\hline كبيرة جدًا & $\wedge \varepsilon, \uparrow$ & 0.96 & 4.23 & تراعي المؤسسات التعليمية الجامعية فرص & 9 \\
\hline كبيرة & $\Lambda r, r$ & 0.86 & 4.11 & تلنمي المؤسسات التعليمية الجامعية قيم تقديم & 5 \\
\hline كبيرة & $\vee \wedge, \varepsilon$ & 1.06 & 3.92 & 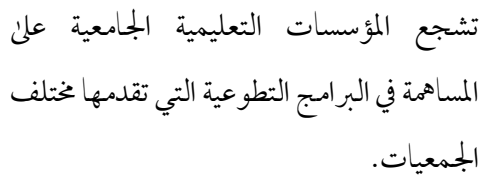 & 7 \\
\hline كبيرة & v^, $\cdot$ & 1.07 & 3.90 & تساعد المؤسسات التعليمية الجامعية علن تقديم & $\varepsilon$ \\
\hline كبيرة & VI, $T$ & 1.14 & 3.88 & المحث المؤسسات التعليمية الجامعية علن الزيارات & r \\
\hline
\end{tabular}

جدول رقم (T): نتائج بجال الإشر اف علئ قيم العمل التطوعي مرتَّبة تنازليًا 


\begin{tabular}{|c|c|c|c|c|c|}
\hline التقدير & المبئ & الاندر اف & المتوسط & الفقرات & 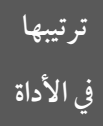 \\
\hline كبيرة & $\vee \vee \tau, \varepsilon$ & 1.07 & 3.82 & 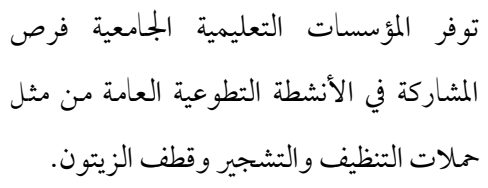 & 7 \\
\hline كبيرة & Vo, 1 & 1.15 & 3.79 & 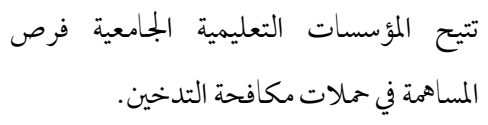 & r \\
\hline كبيرة & Vo & 1.09 & 3.75 & تربط المؤسسات التعليمية الجامعية العمل & 11 \\
\hline كبيرة & $\vee \varepsilon, \varepsilon$ & 0.99 & 3.72 & للموفر المؤسسات التعليمية الجـامعية الفرص & 1 \\
\hline كبيرة & $V \varepsilon, r$ & 0.96 & 3.71 & تعزز المؤسسات التعليمية الجـامعية مفاهيم & 1. \\
\hline كبيرة & $v r, r$ & 1.01 & 3.66 & تقيم المؤسسات التعليمية الجامعية ندوات ثقافية & $\wedge$ \\
\hline كبيرة & 77.25 & 0.60 & 3.86 & الدرجة الكلية & \\
\hline
\end{tabular}

- أنَّ الدرجة الكلية لمتوسطات دور المؤسسات التعليمية الجامعية في الإشر اف علن قيم المشاركة

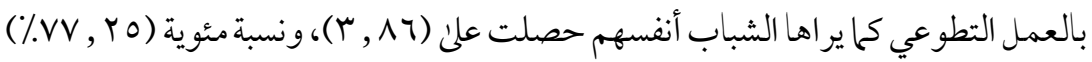

$$
\text { بدرجة كبيرة. }
$$

- كانت أعلى المتوسطات من نصيب الفقرة رقم (9) التي تنص علن" تراعي المؤسسات التعليمية الجامعية فرص المشاركة في العمل التطوعي لكافة الشباب" بمتوسط حسابي

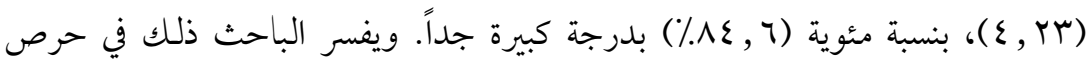
المؤسسات التعليمية لتوفير فرص مشاركة الشباب في العمل التطوعي بدون تمييز، وتسهيل مبادراتهم نحو الزيارات الميدانية والخدمات الاجتماعية والحملات التطوعية. 
- -

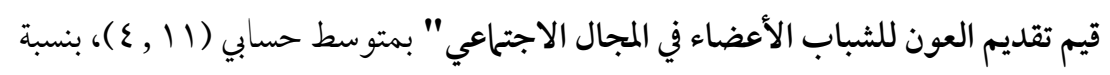

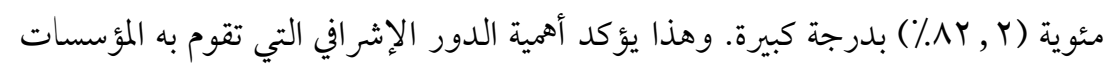

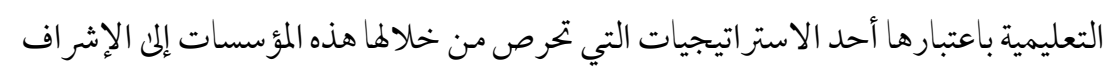
علن العمل التطوعي بشكل متوازن ومتكامل والمتنوع.

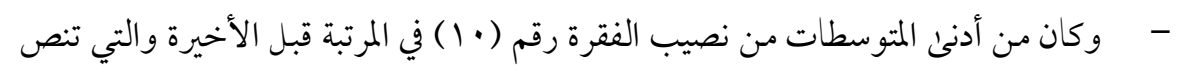

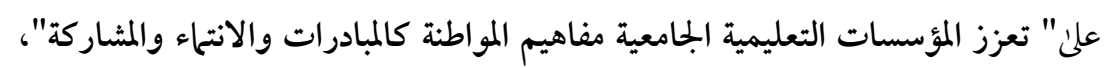

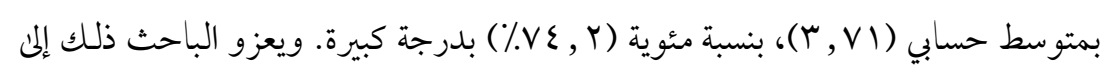

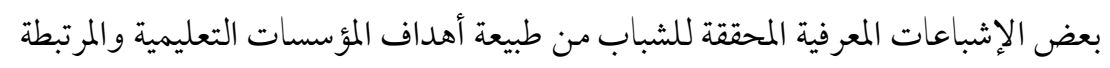

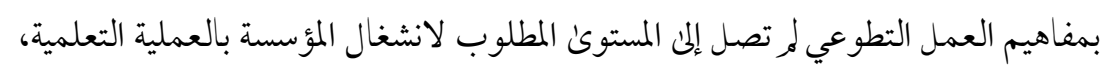

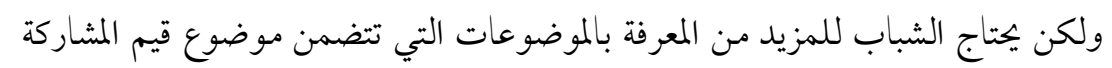

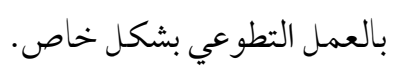

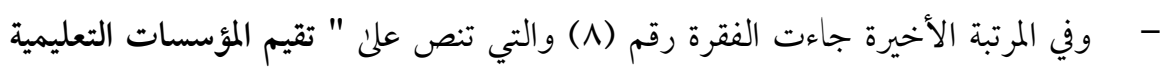

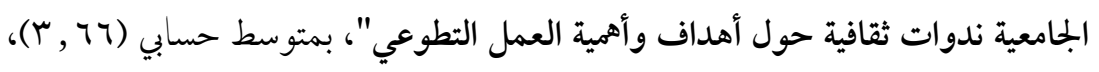

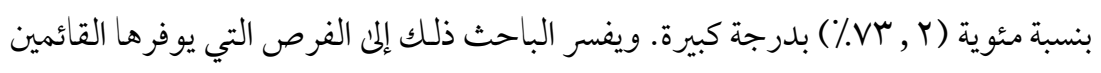

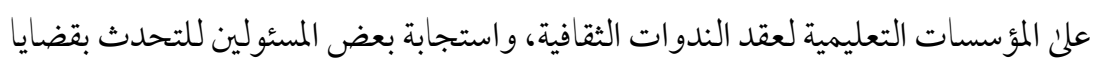

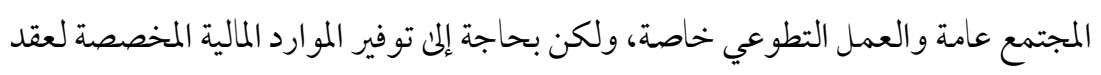
مزيد من الندوات والورش العلمية.

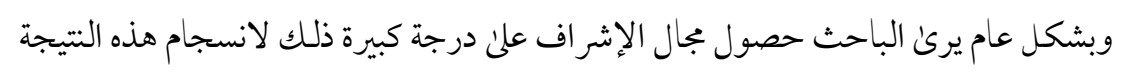

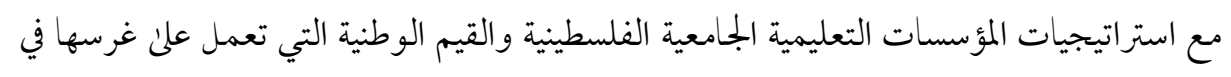

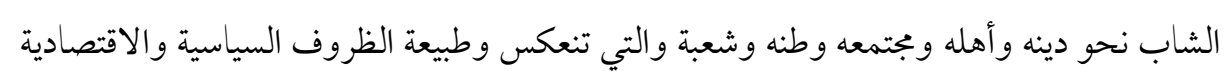

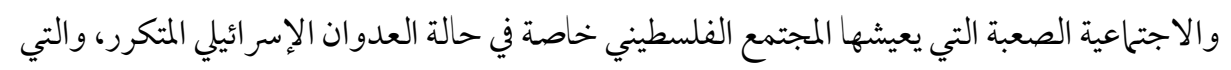


هي أحوج إلى الكثير من العمل التطوعي التي ترتبط بنبض المجتمع وقضاياه وتسمح بالمشاركة لأكبر عدد ممكن من الشباب دون تمييز. واتفقت هذه النتائج مع كل من دراسة عزازي (ع ا • ب)، ودراسة

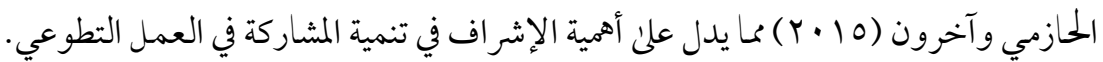
التتائج المتعلقة بالإجابة عن السؤال الرابع ونصه: هل توجد فروق ذات دلالة إحصائية عند مستوى

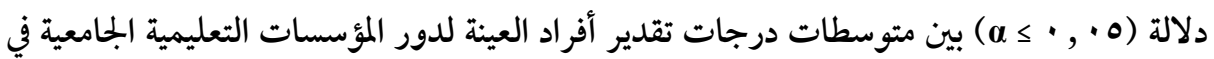
تعزيز قيم مشاركة الشباب الفلسطيني في العمل التطوعي تبعـاً للـمتغيرات: (الجنس، الفئة العمرية، المستوى التعليمي)؟ وللإجابة عن التساؤل السابق قام الباحث بالاختبارات الإحصائية التالية: 1- الفروق في استجابات أفر اد العينة تعزى لمتغير الجنس (ذكر - أنثى): وتم استخدام T-test لعينتين مستقلتين، وكانت النتائج كالتالي: جدول (V): المتوسطات والانحرافات المعيارية وقيمة "T" تعزى إلى متغير الجنس "

\begin{tabular}{|c|c|c|c|c|c|c|}
\hline مستوى الدلالة & $\begin{array}{c}\text { قيمة } \\
T\end{array}$ & الالمحر اف & المسابي & العدد & الجنس & المجال \\
\hline \multirow{2}{*}{ غير دالة } & \multirow{2}{*}{0.998} & 0.643 & 3.926 & $\varepsilon r v$ & ذكور & \multirow{2}{*}{ المجال الأول } \\
\hline & & 0.706 & 3.021 & rat & إناث & \\
\hline \multirow{2}{*}{ غير دالة } & \multirow{2}{*}{0.221} & 0.772 & 3.562 & $\varepsilon r v$ & ذكور & \multirow{2}{*}{ المجال الثاني } \\
\hline & & 0.661 & 3.713 & rat & إناث & \\
\hline \multirow{2}{*}{ غير دالة } & \multirow{2}{*}{0.108} & 0.869 & 3.836 & $\varepsilon r v$ & ذكور & \multirow{2}{*}{ المجال الثالث } \\
\hline & & 0.603 & 3.833 & raq & إناث & \\
\hline \multirow{2}{*}{ غير دالة } & \multirow{2}{*}{$1, \cdots 1$} & $\cdot, V Y I$ & $r, v T \varepsilon$ & $\varepsilon r v$ & ذكور & \multirow{2}{*}{ الدرجة الكلية } \\
\hline & & $\cdot, V r \cdot$ & r r, r & rat & إناث & \\
\hline
\end{tabular}

يتبين من جدول (V) أن قيمة الاحتمال على الدرجة الكلية أكبر من مستوى الدلالة (0 • , • ) وعلن كافة المجالات، وأن قيم (ت) المحسوبة كانت أقل من قيمة (ت) الجلدولية، وهذا يدل علن عدم وجود فروق ذات دلالة إحصائية عند مستون دلالة (0 · , · بين متوسطات تقديرات أفراد عينة 
الدراسة لمجالات دور المؤسسات التعليمية الجامعية في تعزيز قيم مشاركة الشباب الفلسطيني في العمل التطوعي تعزئ إلى متغير الجنس. ويعزو الباحث ذلك أنّ كلا الجنسين لديهم اتجاهات متشابهة نحو ممارسة العمل التطوعي، ونحو الأساليب والآليات اللازمة لتنمية مشاركتهم في العمل التطوعي ونحو فو ائد العمل التطوعي، مما يدل على الرغبة لكلا الجنسين للعمل التطوعي، بالإضافة إلى تشابه ظروفهم الاجتماعية والتعليمية والاقتصادية بدرجة كبيرة، كما أن الشباب بهذه المرحلة يكونو في قمة العطاء والتنافس، وإرساء قو اعد الخير، وبالتالي يكون الذكور و الإناث منخرطين في المشاركة؛ لذا كانت المتو سطات الحسابية متقاربة بين الذكور والإناث علن الدرجة الكلية لكافة مجالات الاستبانة. واختلفت نتائج هذه الدراسة مع دراسة

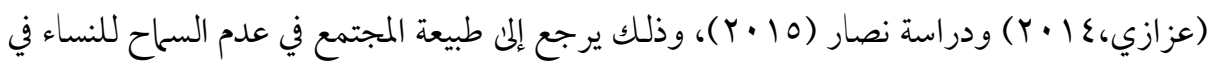
القيام بكافة الأعمال، والخجل وعدم الجر أة وصعوبة الانتقال للمر أة في التطوع بالأماكن العامة عموماً. Y - الفروق في استجابات أفراد العينة تعزى لمتغير الفئة العمرية:

One ( ولتحقق من وجود فروق تعزئ لمتغير الفئة العمرية تم استخدام تحليل التباين الأحادي (Way Anova جدول (^): نتائج تحليل التباين الأحادي تعزئ لمتغير الفئة العمرية

\begin{tabular}{|c|c|c|c|c|c|c|}
\hline مستوى الدلالة & قيمة F & متوسط & درجات & مجموع & مصدر التباين & المجال \\
\hline \multirow{3}{*}{ دالة ل } & \multirow{3}{*}{2.539} & 0.579 & 2 & 1.738 & بين المجموعات & \multirow{3}{*}{ الأول } \\
\hline & & \multirow{2}{*}{0.376} & (N) & 63.601 & داخل المجموعات & \\
\hline & & & ( & 65.339 & المجموع & \\
\hline \multirow{3}{*}{ دالة } & \multirow{3}{*}{3.991} & 0.515 & 2 & 1.738 & بين المجموعات & \multirow{3}{*}{ الثاني } \\
\hline & & \multirow{2}{*}{0.520} & N & 65.601 & داخل المجموعات & \\
\hline & & & ( ) & 66.389 & المجموع & \\
\hline
\end{tabular}

http://dx.doi.org/10.29009/ijres.4.3.6 


\begin{tabular}{|c|c|c|c|c|c|c|}
\hline مستوى & قيمة F F & متوسط & درجات & المربعات & مصدر التباين & المجال \\
\hline \multirow{3}{*}{ دالة ل } & \multirow{3}{*}{4.701} & 0.497 & 2 & 1.490 & بين المجموعات & \multirow{3}{*}{ الثالث } \\
\hline & & \multirow{2}{*}{0.710} & $\Delta \mu_{1}$ & 66.389 & داخل المجموعات & \\
\hline & & & (Nr & $T \vee, \wedge \vee q$ & المجموع & \\
\hline \multirow{3}{*}{ دالة ل } & \multirow{3}{*}{3.078} & 0.206 & 2 & 0.617 & بين المجموعات & \multirow{3}{*}{ الدرجة الكلية } \\
\hline & & \multirow{2}{*}{0.191} & (N) & 32.272 & داخل المجموعات & \\
\hline & & & ( & 32.890 & المجموع & \\
\hline
\end{tabular}

ويلاحظ من هذه النتيجة، أن القيمة الاحتمالية (.Sig) المقابلة لاختبار تحليل التباين الأحادي أكبر من القيمة الجدولية في جميع المجالات، والدرجة الكلية كانت أقل من مستوئ الدلالة (ه • , •)،

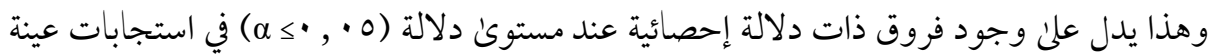
الدراسة على بجالات دور المؤسسات التعليمية الجامعية في تعزيز قيم مشاركة الشباب الفلسطيني في العمل التطوعي تعزئ إلى متغير الفئات العمرية، وباستخدام اختبار شيفيه لمعرفة اتجاه الفروق في استجابات الشباب تبين وجود فروق لصالح الشباب من أصحاب الفئة العمرية من 9 ال-Oب عام، ويرجع ذلك لعدد من الأسباب منها: الطاقة والحيوية التي يمتلكها هذا العمر، والحاجة الخبرة الطويلة في تقديم الأفضل و المشاركة الاجتماعية، كما أن هذه العينة قد حظيت بأهمية في المؤسسات الفلسطينية ولديه الوقت الكافي للمشاركات والتحقت بدورات تدريبيّة، وشاركت في اجتماعات، وندوات، وورش عمل، ولجان بشكل أكبر من أصحاب الفئات العمرية الأكثر، مما يجعل رغبتهم للعمل التطوعي وبجالاتها أكبر. وتتفق النتيجة السابقة في بعض جو انبهامع دراسة العوضي (r ( • ) )، وتختلف مع دراسة نصار 
ץ- الفروق في استجابات أفراد العينة تعزى لمتغير المستوى التعليمي: وللتحقق من وجود فروق تعزئ لمتغير المستوى التعليمي تم استخدام تحليل التباين الأحادي لمعرفة دلالة الفروق بين المجموعات، وكانت النتائج كالتالي: (One Way Anova) جدول (9) : نتائج تحليل التباين الأحادي تعزئ لمتغير المستوكن التعليمي

\begin{tabular}{|c|c|c|c|c|c|c|}
\hline مستوى الدلالة & قيمة F & متوسط & درجات & المربعات & مصدر التباين & المجال \\
\hline \multirow{3}{*}{ غير دالة } & \multirow{3}{*}{$1,9 \varepsilon$} & 2.27 & $r$ & 9.99 & بين المجموعات & \multirow{3}{*}{ الأول } \\
\hline & & \multirow{2}{*}{0.62} & $\Lambda r$. & 54.601 & داخل المجموعات & \\
\hline & & & Tr & 75.339 & المجموع & \\
\hline \multirow{3}{*}{ غير دالة } & \multirow{3}{*}{$\cdot, 91$} & 11.5 & r & 4.53 & بين المجموعات & \multirow{3}{*}{ الثاني } \\
\hline & & \multirow{2}{*}{0.65} & $\Lambda \Gamma$. & 55.601 & داخل المجموعات & \\
\hline & & & 促 & 76.389 & المجموع & \\
\hline \multirow{3}{*}{ غير دالة } & \multirow{3}{*}{$r, r v$} & 4.14 & $r$ & 1.685 & بين المجموعات & \multirow{3}{*}{ الثالث } \\
\hline & & \multirow{2}{*}{0.59} & $\wedge r$. & 86.389 & داخل المجموعات & \\
\hline & & & r & $\wedge \vee ৭ .6$ & المجموع & \\
\hline \multirow{3}{*}{ غير دالة } & \multirow{3}{*}{1,70} & 4.1 & r & 9.33 & بين المجموعات & \multirow{3}{*}{ الدرجة الكلية } \\
\hline & & \multirow{2}{*}{0.5} & $\Lambda r$. & 32.272 & داخل المجموعات & \\
\hline & & & 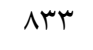 & 32.890 & المجموع & \\
\hline
\end{tabular}

ويلاحظ من هذه النتيجة، أن القيمة الاحتمالية (.Sig) المقابلة لاختبار تحليل التباين الأحادي أقل من القيمة الجدولية في جميع المجالات، والدرجة الكلية كانت أقل من مستوئ الدلالة (0 • , )، وهذا يدل على عدم وجود فروق ذات دلالة إحصائية عند مستوى دلالة (0 • , • $\alpha)$ في استجابات عينة الدراسة على مجالات دور المؤسسات التعليمية الجامعية في تعزيز قيم مشاركة الشباب الفلسطيني في العمل التطوعي تعزئ إلى متغير المستوكئ التعليمي. 
ويعزو الباحث ذلك إلم تشابه الواقع الذي يعيشه الشباب بغض النظر عن المستوئ التعليمي، و المؤسسات الفلسطينية تتكامل في أدوار هما بالرسالة والأهداف كمؤسسات تعليمية عليا لكافة شرائح

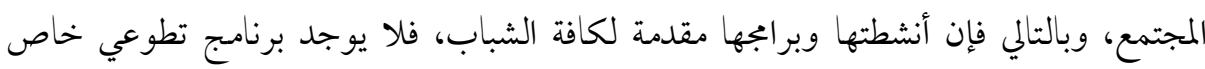
بمستوى تعليمي عن غيرة، وبالتالي فإن الشباب في كافة المستويات التعليمية يحملون نفس الثقافة التطوعية وينتمون لنفس الفلسفة والتي تتضمن العديد من القيم كالقيم الوطنية والمو اطنة والعمل الجحاعي وخدمة المجتمع، مما ترتب علن ذلك عدم وجود فروق لدور المؤسسات الفلسطينية في تعميم ثقافة المشاركة بالعمل التطوعي. وله يحصل الباحث علن دراسات سابقة - في حدود علمه- تناولت المتغير السابق. السيناريوهات المقترحة لتطوير دور المؤسسات التعليمية الجامعية في تعزيز قيم مشاركة الشباب الفلسطيني في العمل التطوعي أ- أسس بناء السيناريوهات المقترح: - - مالمدل النظري للدراسة.

- - الاهتحام الكافي والمُّلح بأهمية تعزيز قيم مشاركة الشباب الفلسطيني في العمل التطوعي.

$$
\text { - - متائج الدراسة الميدانية. }
$$

- - الاهتحام بالشباب الفلسطيني وتطوير قدراتهم وشحذ طاقاتهم وتشجيع الكفاءات.

\section{ب- تصور مقترح للدراسة الحالية:}

بعد استعراض نتائج الدراسة الميدانية ودراسة الوضع الراهن لتقدير الشباب الفلسطيني لمجالات دور المؤسسات التعليمية الجمامعية في تعزيز قيم مشاركة الشباب الفلسطيني في العمل التطوعي، يمكن بناء ثلاثة سيناريوهات مقترحة لتحقيق الرقي بدور المؤسسات الجامعية الفلسطينية فكراً وممارسة كأحدمتطلبات توفير آليات عمل تعزز ضمان جودة عمل المؤسسات التعليمية في فلسطين في تعزيز قيم المشاركة بالعمل التطوعي لدى الشباب، وتشمل: السيناريو المرجعي أو سيناريو الوضع القائم، والسيناريو الاصلاحي، والسيناريو الابتكاري، والتي توضحها الدراسة علن النحو التالي: 


$$
\begin{aligned}
& \text { 1- السيناريو المرجعي (الواقعي أو الامتدادي أو الخطي): } \\
& \text { ينطلق سيناريو الوضع القائم أو السيناريو الامتدادي علن النحو التالي: } \\
& \text { مبررات إعداد السيناريو المرجعي: }
\end{aligned}
$$

- اعفف التمويل والميزانيات المقدمة للمؤسسات التعليمية الجامعية الفلسطينية. - - صعوبة إحداث تغيير جوهري وجذري في المؤسسات التعليمية الجامعية الفلسطينية علن ضوء المسؤولية الاجتماعية تجاه الشباب الفلسطيني في ظل انقسام فلسطيني وضعف الامكانيات.

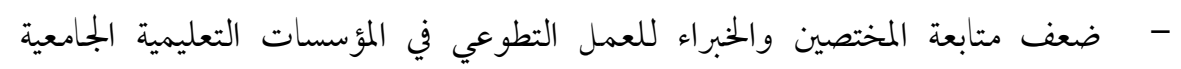
الفلسطينية وفي وضع البرامج التوعوية والإرشادية المقدمة للشباب الفلسطيني. التداعيات المحتملة للسيناريو المرجعي: - استمرار تقديم البرامج والأنشطة التطوعية غير متناسقة مع احتياجات وتطلعات الشباب الفلسطيني والتي أهمها ندرة تو افر خطط واضحة ومحددة بجداول زمنية معينة تلبي تنمية قيم العمل التطوعي لدىن الشباب في ضوء ميولهم واهتحماتهم. - - نفور الشباب من المشاركة في العمل التطوعي في ظل عدم توافر أنظمة تحفيزية ومر اعاة الوقت في تنفيذ الأنشطة.

- - هناك بعض البرامج في المؤسسات التعليمية الفلسطينية التي تتعلق بتحسين مشاركات الشباب، وخلق فرص عمل حقيقية، والمشاركة في إيجاد حلول للمشكلات الاجتماعية والاقتصادية للشباب وهذه يمكن أن تشكل أساساً لتطوير العمل التطوعي. - - توافق العمل التطوعي وتحقيق التنمية المستدامة وحاجة المجتمع في محافظات غزة على وجه الخصوص في تقدير الرؤن والاستراتيجيات التطويرية كاستجابة لثقافة الشباب الفلسطيني، ولكن يبقى الاعتبار الاختلاف والتنوع المجتمعي والبيئي والقانوني والهيكلي، بالإضافة إلى 
الظروف الاقتصادية الصعبة تضعف استراتيجيات المشاركة في الأنشطة التطوعية بين شطري الوطن.

و انطلاقاً لما سبق في إعداد السيناريو المرجعي أو سيناريو الوضع القائم يرئ الباحث أنه لا يشكل أساساً قوي لتطوير دور المؤسسات التعليمية الجامعية في تعزيز قيم مشاركة الشباب الفلسطيني في العمل التطوعي لدئ الشباب، كونه قائم علئ عدة افتراضات واقعية مليئة بالصعوبات والمشكلات

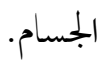

$$
\text { r }
$$

يوضع السيناريو الوسيط أو الإصلاحي لعلاج المشكلات ومواجهة التحديات التي تواجه عملية تطوير دور المؤسسات التعليمية الجامعية في تعزيز قيم مشاركة الشباب الفلسطيني في العمل التطوعي لدئ الشباب، وذلك في حدود الواقع أي إجر اء تحسينات جزيئة دون توافر تغيير جذري على ذلك، ويمكن وصف ذلك السيناريو علئ النحو الآتي: مبررات إعداد السيناريو الوسيط أو الإصلاحي: - - الاستعانة بالمتخصصين، ودعم خطط المؤسسات التعليمية الجامعية الفلسطينية من خلال تقديم المساهمات القائمة علن الأعمال التطوعية وتضمين البعد الاجتماعي فيها. - - محاولة القيام بجولات ميدانية تفقدية للمؤسسات للتعريف بأهمية قيم المشاركة العمل التطوعي، من خلال برامج إعلامية متخصصة، وبث الوعي العام عبر المؤتمرات وورش هُ الم العمل لتعميم ثقافة قيم المشاركة العمل التطوعي. - دم-ج الأعمال التطوعية في خطط واستراتيجيات المؤسسات المحلية، كأنشطة مستمرة تلبي الاحتياجات لفئة الشباب وتستثمر طاقاتهم. - السعي لتوفير هيئة وطنية للمؤسسات الفلسطينية لوضع استراتيجية شاملة كإعداد معايير الوفاء بالعمل التطوعي. 
الثداعيات المحتملة للسيناريو الوسيط أو الإصلاحي:

- - - مإنشاء صندوق خاص بالمؤسسات التعليمية الجامعية الفلسطينية ليكون داعًَا ومساندًا لتنفيذ

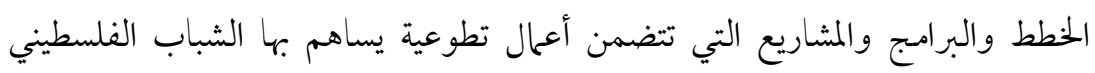

$$
\text { وحسب الامكانيات المتاحة. }
$$

- مشاركة الشخصيات الاعتبارية في عملية دعم المؤسسات التعليمية الجامعية الفلسطينة بمانيات

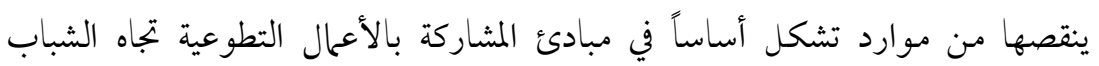
الفلسطيني. - تخصيص منح وجوائز للتميز في أداء الأعمال التطوعية لإضفاء التنافس بين الشباب الفلسطيني من أجل تحقيق تعزيز قيم المشاركة بالعمل التطوعي وتنميتها.

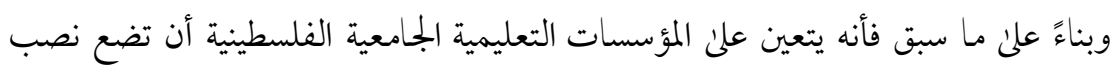

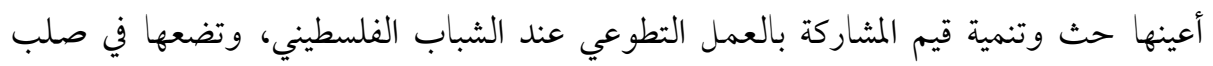

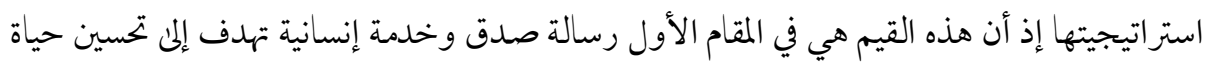

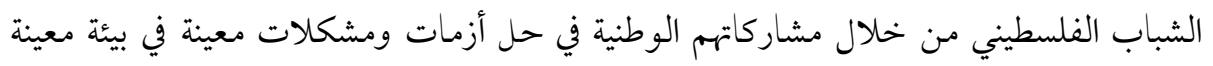

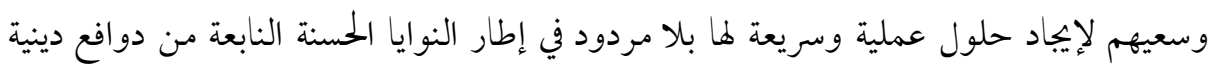
وأخلاقية وإنسانية ووطنية.

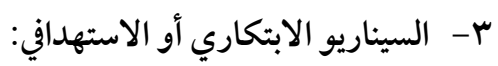
يعتمد هذا السيناريو علن التفكير الإبداعي والابتكاري في علاج جو انب الضعف واستثمار

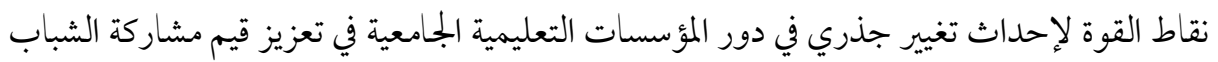

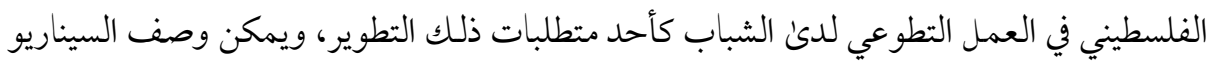

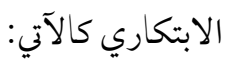


- - حاجة المجتمع الفلسطيني بضرورة تحمل المؤسسات التعليمية الجامعية الفلسطينية تنمية قيم

$$
\text { الشباب الفلسطيني وتلبية احتياجاتهه. }
$$

- - مريظهر تنمية قيم المشاركة بالعمل التطوعي للمؤسسات التعليمية الجامعية في المستوئ المتقدم المطلوب وهذا ما أظهرته الدراسة الميدانية.

- - سيطرة الانقسام الفلسطيني علن جميع أطياف الحياة وكثرة المشكلات بتفعيل الأعلال التطوعية داخل المؤسسات الجمامعية الفلسطينية والتي ربها تضعف مساهمات الشباب الفلسطيني

$$
\text { وتلحق الضرر بالفرد والمجتمع والوطن. }
$$

- - مراعاة حشد الدعم والمساعدة لبرامج الأععال والبرامج والأنشطة التطوعية التي تتبناها

$$
\begin{aligned}
& \text { المؤسسة التعليمية لتنمية الشباب، وتلبي احتياجاتهم. } \\
& \text { التداعيات المحتملة للسيناريو الابتكاري: }
\end{aligned}
$$

- - من المأمول أن تستطيع المؤسسات التعليمية الجمامعية الفلسطينية وضع برامج تحفيز للعمل التطوعي، وتنمية قيم الشباب نحو العمل التطوعي، من خلال الموافقة علن تنظيم المؤتمرات

$$
\text { وورش العمل ودورات التدريب التي تخدم تنمية قيم العمل التطوعي. }
$$

- - إعداد الدراسات والأبحاث حول برامج تطوعية ليستعان بها في تنفيذ برامج المسؤولية المجتمعية للمؤسسة التعليمية الجامعية، وخدمة المجتمع، وإعداد دليل إرشادي بإمكانيات وطاقات الشباب الفعلية بالإضافة إلى تقييم مستوئ أداء المسؤولية المجتمعية ومدئ إسهامها

$$
\text { في تعزيز قيم العمل التطوعي. }
$$

- - من المتوقع إصدار كتيبات لترسيخ قيم العمل التطوعي وتوعية الشباب الفلسطيني بالتعاون مع أجهزة الإعلام لتوجيهه نحو أهداف اجتماعية إنسانية وأخلاقية وتنموية واضحة،

$$
\text { وعرض النماذج الناجحة. }
$$


- وأنشطة تطوعية مشتركة ومتطورة تلبي احتياجات الشباب والمجتمع الفلسطيني، وتمويل جو ائز التميز وأوسمة التقدير بالإضافة إلى تقديم الاستشارات الفنية.

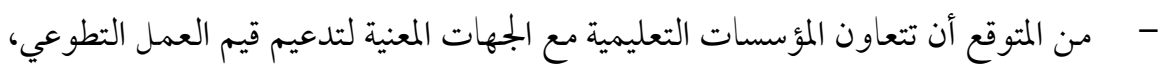

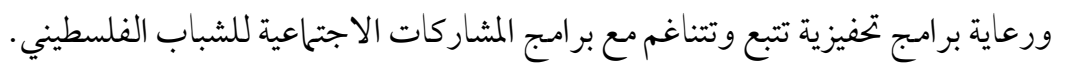

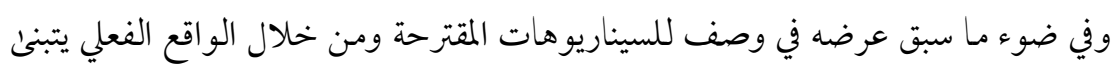

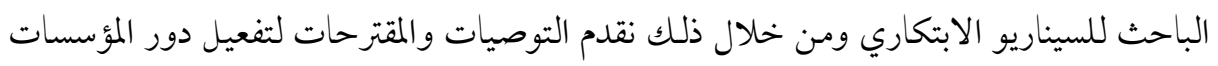

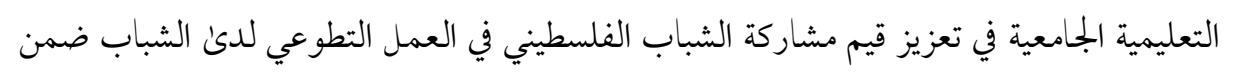

\section{توصيات الدراسة:}

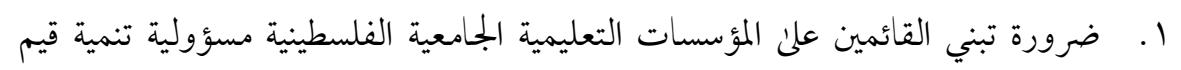

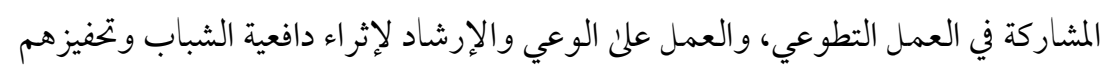

$$
\text { نحو المشاركة بالأعمال التطوعية. }
$$

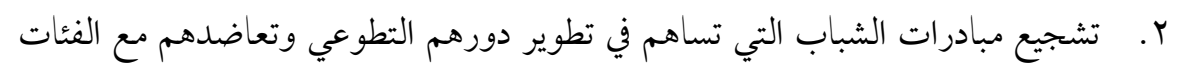
الاجتماعية لمالذلك من أثار ايجابية سواء كانت اقتصادية أو اجتماعية أو معنوية أو وطنية.

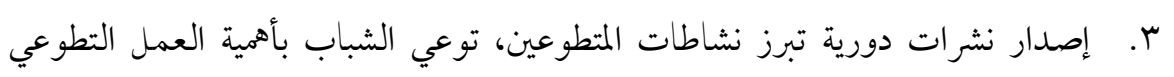

$$
\text { وفو ائده بالنسبة للفرد والمجتمع. }
$$

ع.إصدار مطويات للتعريف بالبرامج التطوعية التي تنظمها المؤسسات الحكومية والأهلية في

$$
\text { المجتمع المحلي. }
$$

0. تطوير إسهامات الشباب نحو العمل التطوعي، من خلال نقل الخبرات الإيجابية في ممارستهم

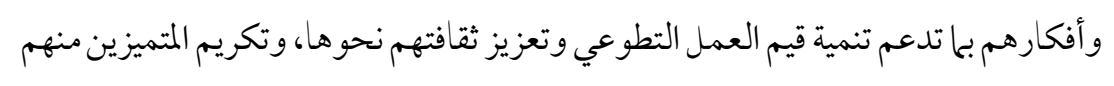

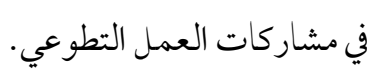


7. تكثيف الورش والندوات والملتقيات ذات العلاقة بتنمية قيم العمل التطوعي وضمان

$$
\text { استمراريته في سلوك الشباب. }
$$

V. رورة التشبيك بين كافة المؤسسات الجامعية والجمعيات الخيرية حتى يكون التعاون مثمر؛

$$
\text { وليتسنى للشباب ترجمة الأفكار إلى سلوك في المشاركة بالأعمال التطوعية. }
$$

^. نشر وتعميم ثقافة المشاركة بالعمل التطوعي في لوحات الإعلانات والنشرات المطبوعة،

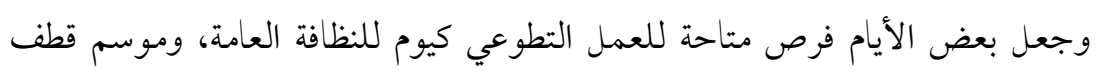

$$
\text { الزيتون، ويوم للصحة. }
$$


1. الألباني، ناصر الدين، السلسلة الصحيحة، وأخرجه ابن أبي الدنيا في (قضاء الحو ائج)، جحس.

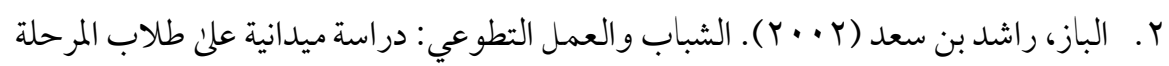

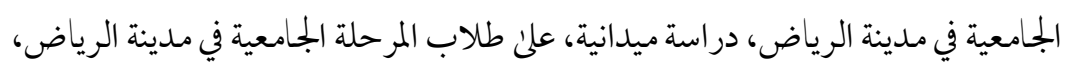

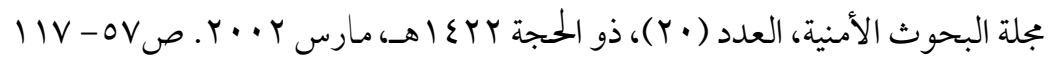

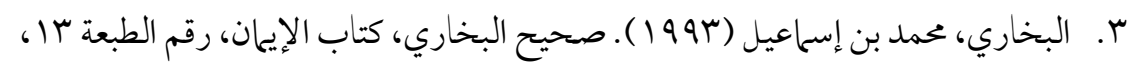

$$
\text { الجزء الأول، دار بن كثير، دمشق: بيروت. }
$$

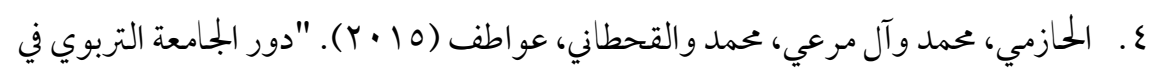

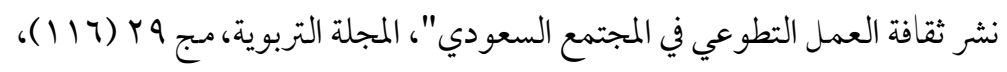

$$
\text { سبتمبر، جامعة الكويت، الكويت. ص } 7 \text { ع }
$$

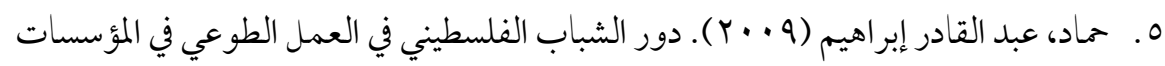

http://www.maannews.net/arb/ViewDetails.aspx?ID=217461 الفلسطينية

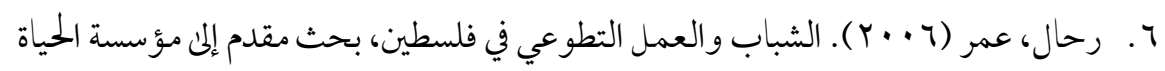
للإغاثة والتنمية، حزير ان، فلسطين. http://www.shams-pal.org/pages/arabic.pdf

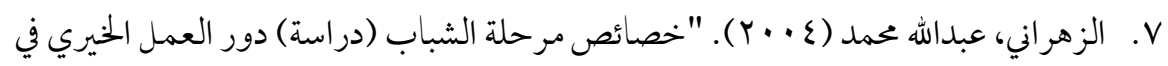
تلبية الحاجات النفسية والاجتماعية والتربوية للشباب كما يراه العاملون في الجمعيات الخيرية بمنطقة الباحة"، المجلة التربوية، العدد (ع ع)، جامعة الكويت، الكويت. ص وليك

$$
\text { rVA-rOI }
$$

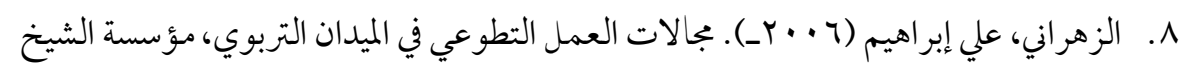
عبدالعزيز بن باز الخيرية، سلسلة مركز الدراسات والبحوث، السعودية.

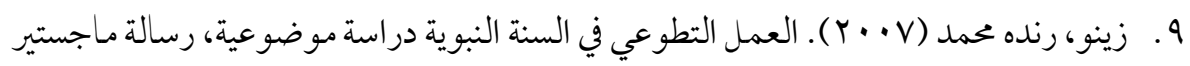
غير منشورة، كلية أصول الدين، الجامعة الاسلامية. 
• 1 ـ الشهراني، معلوي بن عبد الله (7 + . ץ). العمل التطوعي وعلاقته بأمن المجتمع، دراسة ماجستير غير منشورة، قسم العلوم الاجتماعية، جامعة نايف الامنية.

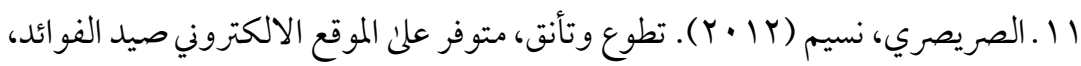
www.saaid.net

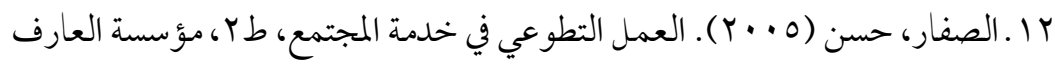

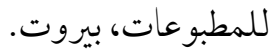

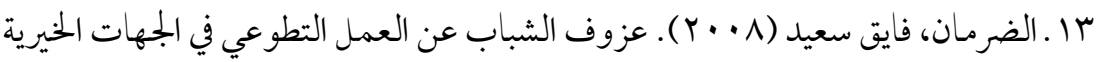
بمنطقة الباحة من وجهة نظر القائمين عليها، السعودية، http://www.alkutubcafe.com/book/8QffvX.html

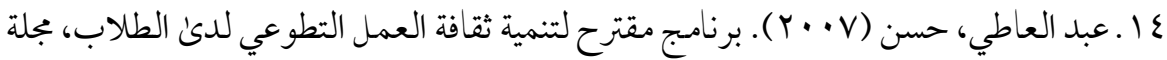

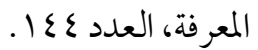

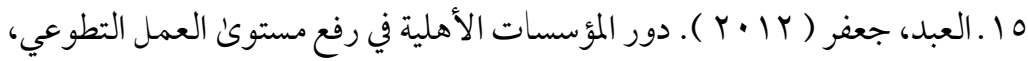
www.qateefiat.com

7 ا ـعزازي، فاتن محمد (ع ا • ؟). "تدعيم العمل التطوعي داخل الجامعات السعودية: مدخل استراتيجي"، المجلة الدولية التربوية المتخصصة، المجلد (r)، العدد (ع)، نيسان، ص $.1 \Lambda r-17 T$

V ا ـ العوضي، رأفت (ب ا • Y). دور المؤسسات التعليمية في تعميم ثقافــــــة المشاركة بالعمل التطوعي من وجهة نظر الطلبة (دراسة ميدانية - كلية التنمية الاجتماعية والأسرية بجامعة القدس المفتوحة نموذجاً)، بحث مقدم لمؤتمر العمل التطوعي في فلسطين، جامعة القدس

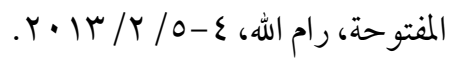

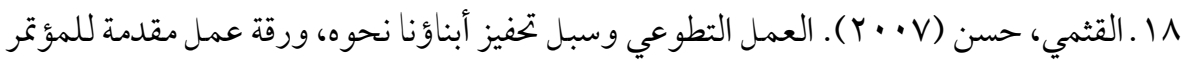

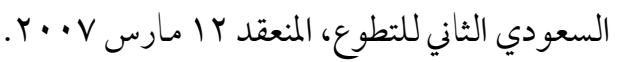

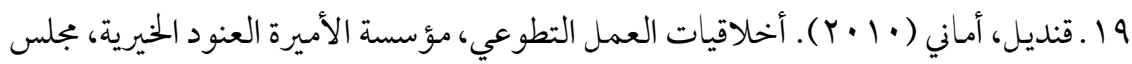
وزراء العمل والشؤون الاجتماعية بدول بجلس التعاون. 


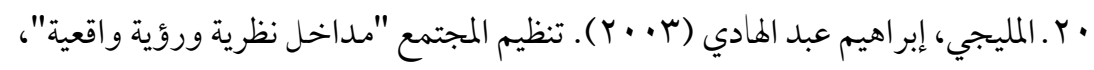
الإسكندرية: المكتب الجامعي الحديث.

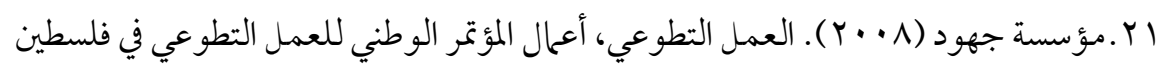
و الذي نظمته مؤسسة جهود في مدينة رام الله بدعم من مكتب مبادرات الشر اكة الشرق اوسطية MEPI، حزيران، رام الله، فلسطين، - http://www.alhayat j.com/details.php?opt=3\&id=67583\&cid

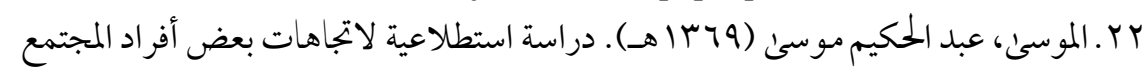

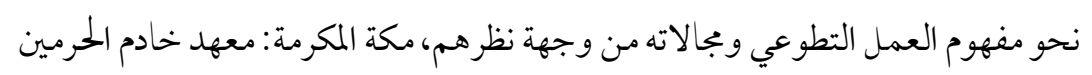
الشريفين لأبحاث الحجه، المملكة العربية السعودية.

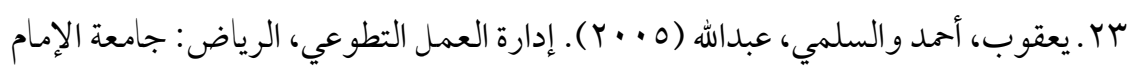
محمد بن سعود الإسلامية، علادة البحث العلمي. 


\section{References:}

- Home Office, (2004). A review of the Home office older volunteers Initiative ,Research Study (248), London:at:

officehttps://www.gov.uk/government/organisations 
